\title{
Insulin-like growth factor-I protects cells from ER stress-induced apoptosis via enhancement of the adaptive capacity of endoplasmic reticulum
}

\author{
R Novosyadlyy ${ }^{1}$, N Kurshan ${ }^{1}$, D Lann ${ }^{1}$, A Vijayakumar ${ }^{1}$, S Yakar ${ }^{1}$ and D LeRoith ${ }^{\star, 1}$
}

Disruption of endoplasmic reticulum (ER) homeostasis causes accumulation of unfolded and misfolded proteins in the ER, triggering the ER stress response, which can eventually lead to apoptosis when ER dysfunction is severe or prolonged. Here we demonstrate that human MCF-7 breast cancer cells, as well as murine NIH/3T3 fibroblasts, are rescued from ER stress-initiated apoptosis by insulin-like growth factor-I (IGF-I). IGF-I significantly augments the adaptive capacity of the ER by enhancing compensatory mechanisms such as the IRE1 $\alpha$-, PERK- and ATF6-mediated arms of ER stress signalling. During ER stress, IGF-I stimulates translational recovery and induces expression of the key molecular chaperone protein Grp78/BiP, thereby enhancing the folding capacity of the ER and promoting recovery from ER stress. We also demonstrate that the antiapoptotic activity of IGF-I during ER stress may be mediated by a novel, as yet unidentified, signalling pathway(s). Application of signal transduction inhibitors of MEK (U1026), PI3K (LY294002 and wortmannin), JNK (SP600125), p38 (SB203580), protein kinases A and C (H-89 and staurosporine) and STAT3 (Stattic) does not prevent IGF-I-mediated protection from ER stress-induced apoptosis. Taken together, these data demonstrate that IGF-I protects against ER stress-induced apoptosis by increasing adaptive mechanisms through enhancement of ER stress-signalling pathways, thereby restoring ER homeostasis and preventing apoptosis.

Cell Death and Differentiation (2008) 15, 1304-1317; doi:10.1038/cdd.2008.52; published online 25 April 2008

Apoptotic cell death can be initiated by extrinsic (receptormediated) or intrinsic (organelle-mediated) signalling pathways that induce death-associated proteolytic and/or nucleolytic activities. ${ }^{1}$ The intrinsic pathway of apoptosis involves suicidal signalling programs triggered by intracellular organelles when their internal homeostasis is disrupted. Until now, such an apoptogenic activity has been ascribed to the nucleus, mitochondrion and cell membrane. ${ }^{1-3}$ Recently, it has been shown that disturbances in endoplasmic reticulum (ER) homeostasis lead to an evolutionarily conserved cell response (unfolded protein response or ER stress), which also eventually triggers apoptosis. ${ }^{4}$ ER homeostasis can be disrupted by numerous factors, including accumulation of unfolded and misfolded proteins, calcium depletion, glucose deprivation, accumulation of free cholesterol and viral infection. ${ }^{5,6}$ It is believed that the primary biological goal of the ER stress response is not to induce apoptosis, but to re-establish normal function of the ER. At the molecular level, this response involves translational repression, increased folding capacity of the ER and degradation of improperly folded proteins. ${ }^{4}$ These effects are mediated by numerous compo- nents of ER stress signalling, including activating transcription factor-6 (ATF6), inositol-requiring ER-to-nucleus signal kinase-1 $\alpha(\operatorname{IRE} 1 \alpha)$ and PRK (RNA-dependent protein kinase)like ER kinase (PERK). ATF6 is a transmembrane protein that is cleaved from the ER membrane and translocates to the nucleus during ER stress. Cleaved ATF6 binds to the promoter of genes that encode proteins involved in restoration of ER homeostasis. Activation of IRE $1 \alpha$ results in processing of mRNA that encodes another transcription factor, X-boxbinding protein-1 (XBP-1). This leads to accumulation of the active XBP-1 protein, which has a similar role to ATF6. In parallel, ER stress activates PERK, which phosphorylates eukaryotic translation initiation factor- $2 \alpha$ (elF2 $\alpha)$, resulting in downregulation of the biosynthetic load of the ER by inhibiting protein synthesis and inducing activating transcription factor (ATF4) translation. ${ }^{4}$ All three arms of ER stress-signalling system are capable of inducing transcription of growth arrestand DNA damage-inducible gene 153/C/EBP homologous protein (GADD153/CHOP), a powerful transcription factor that plays a pivotal role in ER stress response. ${ }^{7}$ However, if ER dysfunction is severe or prolonged, these compensatory

\footnotetext{
${ }^{1}$ Division of Endocrinology, Diabetes and Bone Diseases, The Samuel Bronfman Department of Medicine, Mount Sinai School of Medicine, New York, NY, USA *Corresponding author: D LeRoith, Division of Endocrinology, Diabetes and Bone Diseases, The Samuel Bronfman Department of Medicine, Mount Sinai School of Medicine, One Gustave L Levy Place, Box 1055, New York, NY 10029, USA.

Tel: + 1212241 6306; Fax: + 1212241 4218;

E-mail: derek.leroith@mssm.edu

Keywords: endoplasmic reticulum; IGF; apoptosis

Abbreviations: ATF4, activating transcription factor 4; ATF6, activating transcription factor 6; elF2 $\alpha$, eukaryotic translation initiation factor $2 \alpha$; ER, endoplasmic reticulum; ERK1/2, extracellular signal-regulated kinases 1 and 2; GADD153/CHOP, growth arrest- and DNA damage-inducible gene 153/C/EBP homologous protein; GADD34, growth arrest- and DNA damage-inducible gene; IGF-I, insulin-like growth factor-l; IRE1 $\alpha$, inositol-requiring ER-to-nucleus signal kinase-1 $\alpha$; JNK, c-Jun N-terminal kinase; MAPK, mitogen-activated protein kinase; MEK, MAPK/ERK kinase; PARP, poly-(ADP ribose) polymerase; PERK, PRK (RNA-dependent protein kinase)-like ER kinase; PI3K, phosphatidylinositol-triphosphate kinase; PKA, protein kinase A; PKC, protein kinase C; SERCA, sarcoendoplasmic reticulum calcium ATPase; STAT3, signal transducer and activator of transcription 3; XBP-1, X-box binding protein-1

Received 04.7.07; revised 12.3.08; accepted 14.3.08; Edited by JA Cidlowski; published online 25.4.08
} 
mechanisms fail and ER stress induces an apoptogenic program. ER stress-induced apoptosis is an essential step in the pathogenesis of neurodegenerative diseases, atherosclerosis, obesity and certain forms of diabetes, ${ }^{5,8,9}$ and its inhibition seems to be an attractive therapeutic target. On the other hand, induction of ER stress in rapidly dividing and biochemically active cancer cells represents an alternative approach that can be used for cessation of tumor progression and metastasis. ${ }^{10}$

Insulin-like growth factor-I (IGF-I) plays a crucial role in regulation of cell survival, proliferation, differentiation and metabolism. ${ }^{11,12}$ The biological effects of IGF-I are mediated via IGF-I receptor (IGF-IR), which belongs to the family of receptor tyrosine kinases. Upon ligand binding and receptor autophosphorylation, the IGF-IR eventually activates two principal signalling pathways, the mitogen-activated protein kinase (MAPK) pathway and the phosphatidylinositol-triphosphate kinase (PI3K) pathway. ${ }^{13,14}$ IGF-I-mediated signal transduction through MAPK pathway results in activation of extracellular signal-regulated kinases 1 and 2 (ERK1/2). ${ }^{15}$ Other terminal MAP kinases, such as c-Jun N-terminal kinase (JNK) and p38 kinase, are primarily activated by environmental stressors, but several lines of evidence suggest that they can also be activated in response to IGF-I. ${ }^{16-18}$ Although PI3K pathway plays a major role in insulin- and IGF-I-induced cell survival, ${ }^{19}$ the MAPK signalling pathway also underlies the antiapoptotic effect of IGF-I in some cell types and with certain apoptosis-inducing stimuli. ${ }^{15,17,18,20}$

This study focuses on the role of IGF-I in ER stress. We demonstrate that ER stress-induced apoptosis can be rapidly induced in normal and malignant cell types, and that IGF-I is a powerful factor that protects cells from the lethal consequences of ER stress. Moreover, we show that ER stress signalling pathways, which mediate the adaptive stress response, are markedly enhanced by IGF-I. Finally, we demonstrate that during ER stress, IGF-I does not exert its antiapoptotic activity through its canonical signal transduction pathways.

\section{Results}

ER stress-induced apoptosis is markedly and rapidly induced in human MCF-7 breast cancer cells and mouse NIH/3T3 fibroblasts. ER stress was induced in cultured cells using thapsigargin (sarcoendoplasmic reticulum calcium ATPase (SERCA) inhibitor, $1 \mu \mathrm{M}$ ), tunicamycin (inhibitor of $N$-linked glycosylation, $5 \mu \mathrm{g} / \mathrm{ml}$ ), dithiothreitol (disruptor of disulfide bonds, $1 \mathrm{mmol} / \mathrm{l}$ ), brefeldin A (Golgi disruptor, $5 \mu \mathrm{g} / \mathrm{ml}$ ) and epoxomicin (inhibitor of proteasomal degradation, $1 \mu \mathrm{M}$ ). MCF-7, PC-3 and NIH/3T3 cells were treated in the presence or absence of ER stress inducers for $24 \mathrm{~h}$. Cleaved poly-(ADP ribose)-polymerase (PARP) is considered an early marker of apoptosis. Most ER stress inducers caused marked apoptosis in human mammary carcinoma MCF-7 cells and mouse NIH/3T3 fibroblasts, whereas human prostate PC-3 carcinoma cells were considerably less sensitive to ER-stress-induced apoptosis. In both MCF-7 and NIH/3T3 cells, thapsigargin demonstrated the most prominent apoptogenic effect (Figure 1a).
Estradiol does not inhibit ER stress-induced apoptosis. Treatment with thapsigargin for $3 \mathrm{~h}$ resulted in marked apoptosis in MCF-7 cells. Since estrogens are important factors for growth and survival of normal and transformed mammary epithelial cells, we studied the effect of $\beta$-estradiol on thapsigargin-induced apoptosis in estrogen receptor-positive mammary carcinoma MCF-7 cells. Addition of $\beta$-estradiol $(10 \mathrm{nM})$ did not protect from ER stress-induced apoptosis (Figure 1b). The biological activity of $\beta$-estradiol was confirmed by western blot analysis, which demonstrated that estradiol $(10 \mathrm{nM})$ was capable of inducing phosphorylation of ERK1/2 and Akt in MCF-7 cells (data not shown).

IGF-I protects from ER stress-induced apoptosis. In contrast to estradiol, IGF-I demonstrated powerful antiapoptotic activity (Figure 1c). In MCF-7 cells, IGF-I abrogated the apoptogenic effect of thapsigargin at early time points $(3-12 \mathrm{~h})$ (Figure 1c). Tunicamycin-induced apoptosis was also prevented by IGF-I in MCF-7 cells (data not shown). However, at later time points $(24 \mathrm{~h})$, the antiapoptotic effect of IGF-I was less prominent, even when a relatively low concentration of thapsigargin $(100 \mathrm{nM})$ was used (Figure 1d). A similar time course of the antiapoptotic activity of IGF-I during thapsigargin- and tunicamycininduced apoptosis was observed in mouse NIH/3T3 fibroblasts (data not shown). Since PARP can also be cleaved during necrosis, an alternative, and more specific technique, was employed. In both MCF-7 and NIH/3T3 cells, apoptosis was evaluated by Cell Death Detection ELISA, which determined the level of histone-associated DNA in the cytosolic fraction of cells treated with thapsigargin in the presence or absence of IGF-I. This approach also identified IGF-I as a powerful protector against thapsigargin-induced apoptosis in both cell types (Figure 1e).

IGF-I potentiates adaptive mechanisms via enhancement of the ER stress signalling system. During ER stress, an adequate adaptive response mediated by the unique ER stress signalling system is a major factor in the recovery of ER homeostasis and prevention of apoptosis. $^{21,22}$ To evaluate whether IGF-I regulates this adaptive response, we exposed MCF-7 cells to thapsigargin in the presence or absence of IGF-I. ER-stress signalling is initiated by three sensors of ER homeostasis, including PERK, IRE $1 \alpha$ and ATF6. Upon activation, these molecules activate downstream transcription factors that induce expression of genes involved in restoring ER function. The downstream transcription factor GADD153/CHOP is a convergence point for the three arms of ER-stress signal transduction. ${ }^{7}$ In both MCF-7 cells and NIH/3T3 fibroblasts, GADD153/CHOP was induced by thapsigargin (1000 nM) in a time-dependent manner, with maximum effect at $12 \mathrm{~h}$ (Figure 2a). Addition of IGF-I to thapsigargin-treated cultures significantly increased GADD153/CHOP protein levels. Treatment with IGF-I alone, however, did not result in GADD153/CHOP induction in MCF-7 cells, whereas in NIH/ 3T3 fibroblasts GADD153/CHOP expression was weakly induced in a time-dependent manner (Figure 2b). To investigate whether GADD153/CHOP deletion protects 
a

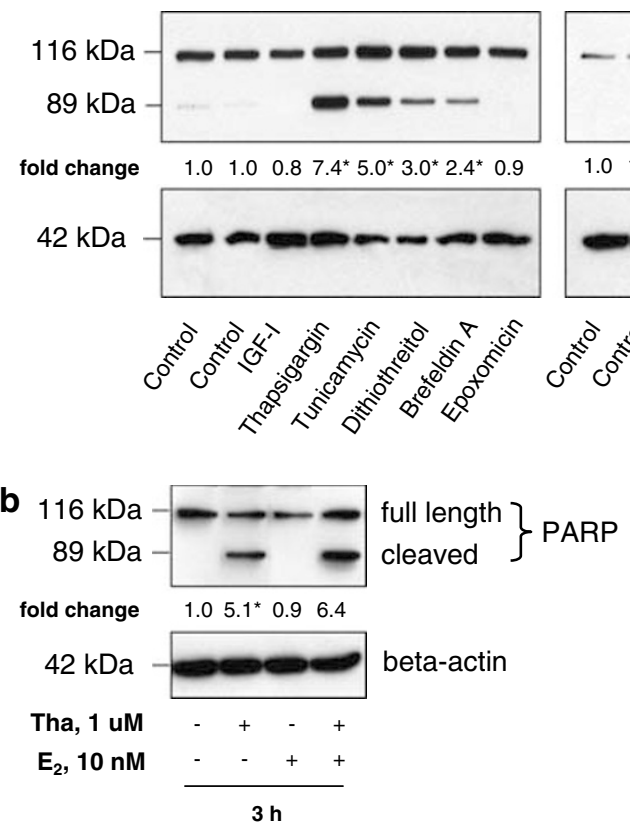

$3 \mathbf{h}$

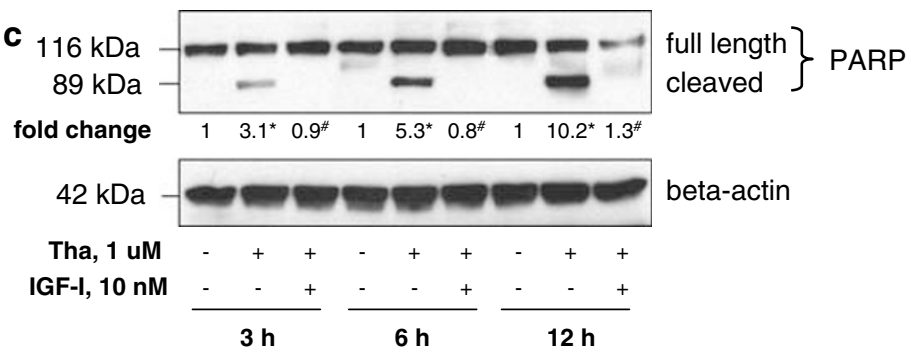

MCF-7 cells

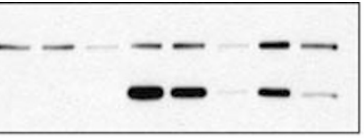

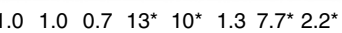
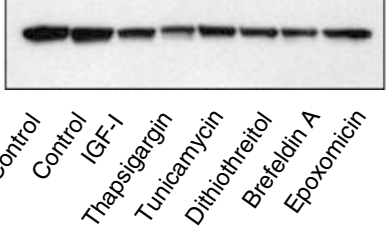

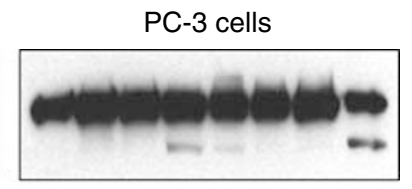

$\begin{array}{llllllll}1.0 & 1.0 & 0.9 & 2.0^{*} & 1.2 & 0.8 & 0.6 & 2.7^{*}\end{array}$

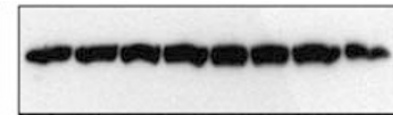

beta-actin beta-actin

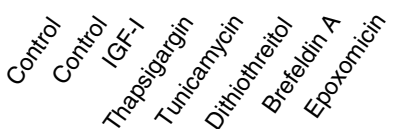
$\left.\begin{array}{l}\text { full length } \\ \text { cleaved }\end{array}\right\}$ PARP
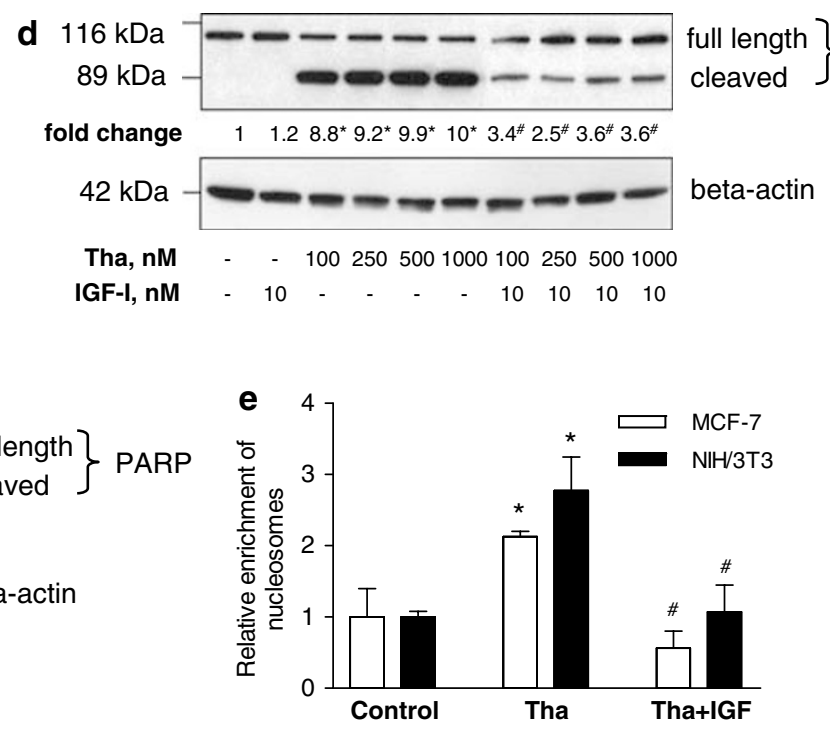

Figure 1 (a) Mouse NIH/3T3 fibroblasts, human MCF-7 breast cancer cells and human PC-3 prostate cancer cells were incubated in serum-free medium in the presence of IGF-I ( $10 \mathrm{nM}$ ), thapsigargin (SERCA inhibitor, $1 \mu \mathrm{M}$ ), tunicamycin (inhibitor of $N$-linked glycosylation, $5 \mu \mathrm{g} / \mathrm{ml}$ ), dithiothreitol (disruptor of disulfide bonds, $1 \mathrm{mmol} / \mathrm{l}$ ), brefeldin A (Golgi disruptor, $5 \mu \mathrm{g} / \mathrm{ml}$ ) and epoxomicin (inhibitor of proteasomal degradation, $1 \mu \mathrm{M}$ ) for $24 \mathrm{~h}$. (b) MCF-7 cells were incubated in serum-free medium in the presence of thapsigargin $(1 \mu \mathrm{M})$ and/or $\beta$-estradiol $(10 \mathrm{nM})$ for $3 \mathrm{~h}$. (c) MCF-7 cells were incubated in the presence of thapsigargin $(1 \mu \mathrm{M})$ and/or IGF-I (10 nM) for 3,6 and $12 \mathrm{~h}$. (d) MCF-7 cells were incubated in serum-free medium in the presence of different concentrations of thapsigargin $(0.1-1 \mu \mathrm{M})$ with or without IGF-I (10 nM) for $24 \mathrm{~h}$. Proteins ( $25 \mu \mathrm{g})$ extracted from whole-cell lysates were size-fractionated by SDS-PAGE and immunoblotted with anti-PARP antibodies. Apoptosis was evaluated by PARP cleavage. Equal loading of proteins was demonstrated by immunoblotting with an antibody directed against beta-actin. The experiments were replicated three times and representative autoradiographs are presented. The results of densitometric analysis are presented as a fold change compared to untreated cells. Statistically significant difference is presented as follows: $P<0.05$ versus untreated (*) or thapsigargin-treated (\#) cultures. (e) MCF-7 (open bars) and NIH/3T3 (solid bars) cells were incubated in the presence of thapsigargin $(1 \mu \mathrm{M})$ and/or IGF-I $(10 \mathrm{nM})$ for $12 \mathrm{~h}$, and apoptosis was evaluated by Cell Death Detection ELISA according to the manufacturer's instructions. The results are expressed as a relative enrichment of nucleosomes in the cytoplasm of thapsigargin- and thapsigargin/IGF-I-treated cells compared with in the untreated controls. Statistically significant difference is presented as follows: $P<0.05$ versus untreated $\left(^{*}\right)$ or thapsigargin-treated (\#) cultures (Student's $t$-test)

from apoptosis induced by thapsigargin, we used SV40 Tantigen-immortalized fibroblasts derived from wild type and GADD153/CHOP-knockout mouse embryos. Our results demonstrate that only tunicamycin-induced apoptosis was attenuated in GADD153/CHOP-deficient cells (Figure 2c). The rate of thapsigargin-induced apoptosis was the same in wild-type and GADD153/CHOP-knockout MEFs. To identify the mechanism that is involved in IGF-I-mediated potentiation of GADD153/CHOP expression, we studied the effect of IGF-I on the IRE $1 \alpha$, ATF6 and PERK pathways activated by ER stress in MCF-7 cells (Figures 3 and 4 ) and $\mathrm{NIH} / 3 \mathrm{~T} 3$ fibroblasts (Figure 5). IRE $1 \alpha$ is an ER-resident transmembrane protein kinase whose activity is regulated by autophosphorylation. In mammalian cells, IRE $1 \alpha$ activation is required for expression of the active form of XBP-1, a transcription factor that plays an important role in recovery from ER stress. ${ }^{21,22}$ Our data demonstrate that during thapsigargin-induced ER stress, IGF-I potentiates IRE1 $\alpha$ phosphorylation (Figures $3 a$ and $5 a$ ), stimulates splicing of XBP-1 mRNA and leads to accumulation of active XBP-1 in the cell and nucleus (Figures $3 b$ and $5 a$ ). Purity of nuclear extracts was demonstrated by western blot analysis with antiPARP antibodies (Figure 3d). We further explored the activity of the ATF6 pathway, a second arm of ER stress-signalling system. ATF6 is an ER-resident transmembrane protein, which undergoes a complex cleavage in the ER and Golgi 
a

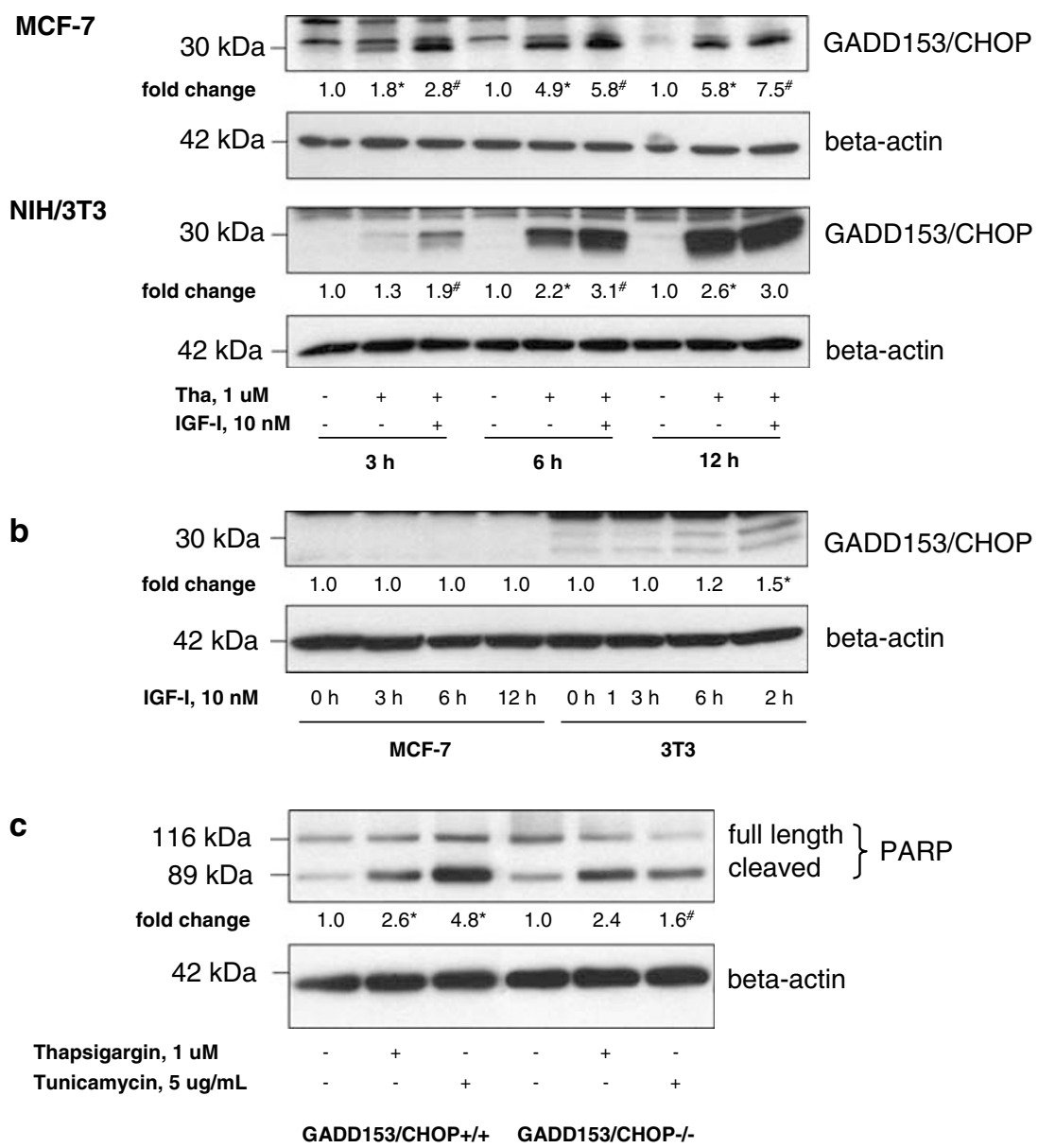

Figure 2 (a) MCF-7 cells and NIH/3T3 fibroblasts were incubated with thapsigargin ( $1 \mu \mathrm{M})$ and/or IGF-I ( $10 \mathrm{nM})$ for 3,6 and $12 \mathrm{~h}$. (b) MCF-7 cells and NIH/3T3 fibroblasts were incubated with IGF-I (10 nM) for 3, 6 and $12 \mathrm{~h}$. (c) SV40 T-antigen-immortalized GADD153/CHOP $+/+$ and GADD153/CHOP-I- mouse embryo fibroblasts were incubated in serum-free medium in the presence of thapsigargin $(1 \mu \mathrm{M})$ or tunicamycin $(5 \mu \mathrm{g} / \mathrm{ml})$ for $24 \mathrm{~h}$. Control cultures were maintained in serum-free medium. Proteins $(25 \mu \mathrm{g})$ extracted from whole-cell lysates were size-fractionated by SDS-PAGE and immunoblotted with anti-GADD153/CHOP (a, b) and anti-PARP (c) antibodies. Equal loading of proteins was demonstrated by immunoblotting with an antibody directed against $\beta$-actin. The experiments were replicated three times and representative autoradiographs are presented. The results of densitometric analysis are presented as a fold change compared with untreated cells. Statistically significant difference is presented as follows: $P<0.05$ versus untreated $\left({ }^{*}\right)$ or thapsigargin-treated (\#) cultures (Student's $t$-test). In the last experiment, the difference in the rate of PARP cleavage was compared with the respective untreated $\left(^{*}\right)$ and thapsigragin- or tunicamycin-treated GADD153/CHOP $+1+$ cells (\#)

apparatus during ER stress and eventually translocates to the nucleus where it regulates expression of multiple genes involved in the restoration of ER's function. ${ }^{21,22}$ The addition of IGF-I to thapsigargin-treated cells results in significant accumulation of cleaved ATF6 in the nucleus (Figures $3 \mathrm{c}$ and $5 b)$. PERK is another ER-resident protein kinase, which initiates the third signalling pathway implicated in ER stress and is also activated by autophosphorylation. Active PERK is known to phosphorylate, and thereby inactivate, elF2 $\alpha$, eventually leading to a global translational repression followed by induction of ATF4 translation. ${ }^{21,22}$ During thapsigargininduced ER stress, IGF-I significantly enhances PERK phosphorylation (Figures $4 a$ and $5 a$ ) and increases cellular and nuclear levels of ATF4 (Figures $4 b$ and $5 b$ ). In contrast, elF2 $\alpha$ phosphorylation decreases after addition of IGF-I (Figures $4 a$ and $5 a$ ). Dephosphorylation of elF2 $\alpha$ is controlled by the ER stress-inducible gene Gadd34, which encodes a regulatory protein that recruits and activates the catalytic subunit of PP1c. The activation of this cellular phosphatase represents a negative feedback loop, which dephosphorylates elF2 $\alpha$ and provides recovery from ER stress-induced translational repression. ${ }^{21,22}$ ER stress-signalling pathways activate GADD153/CHOP, ${ }^{7}$ which directly induces GADD34 gene expression. ${ }^{23}$ Our data suggest that IGF-I-induced reduction of elF2 $\alpha$ phosphorylation might be mediated by GADD34 (growth arrest- and DNA damage-inducible gene) (Figure 5a). Furthermore, abundance of GADD34 correlates with the kinetics of elF2a dephosphorylation. Therefore, during thapsigargin-induced ER stress, IGF-I potentiates elF2 $\alpha$ phosphatase activity by enhancing GADD34 expression that mediates faster recovery from translational repression. Taken together, these data imply that during ER stress, IGF-I augments ER stress signalling systems, including IRE $1 \alpha$, ATF6 and PERK pathways. 

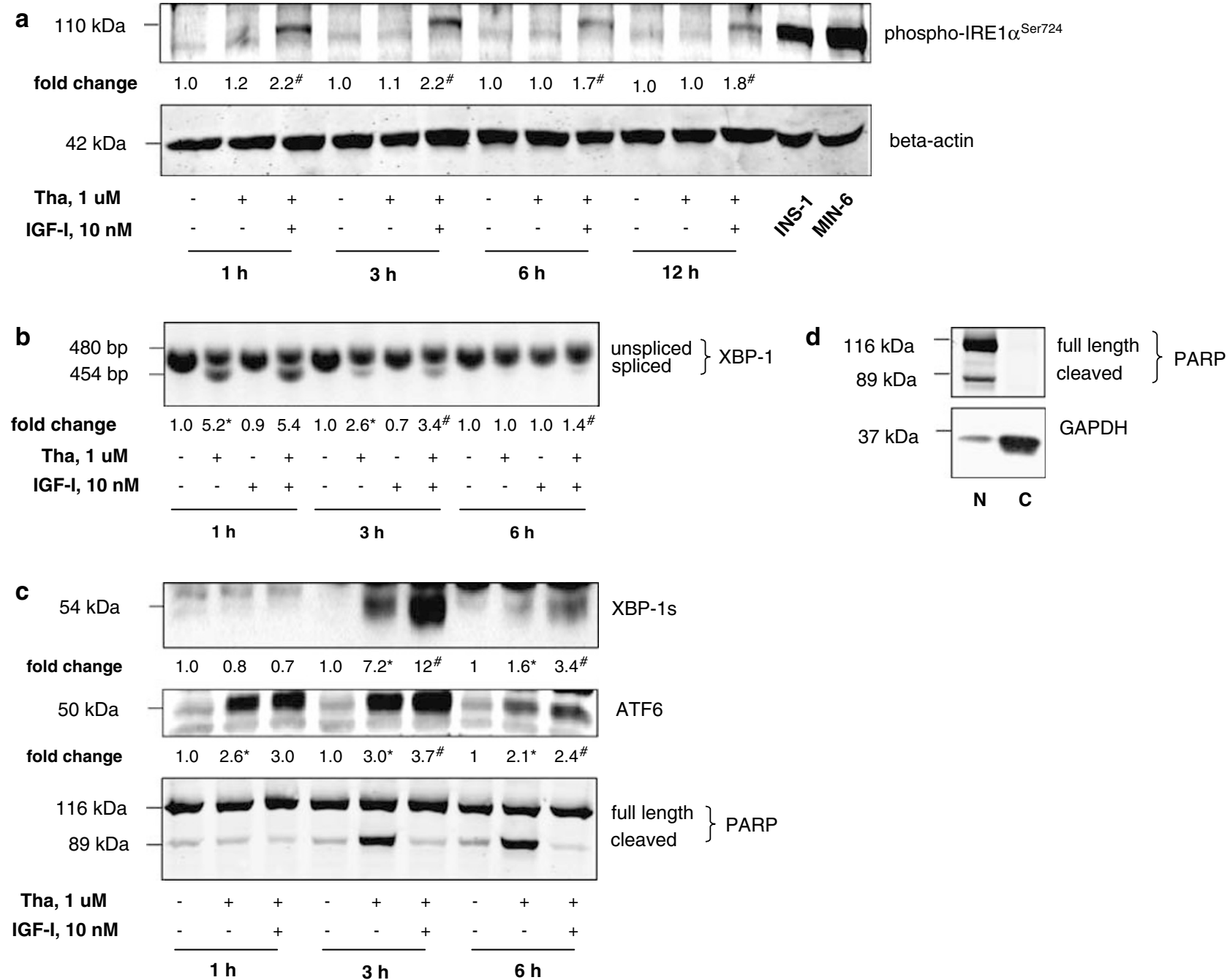

Figure 3 (a) MCF-7 cells were incubated with thapsigargin $(1 \mu \mathrm{M})$ and/or IGF-I (10 nM) for 1, 3, 6 and $12 \mathrm{~h}$. Control cultures were maintained in serum-free medium Rodent $\beta$-cell lines INS-1 and MIN-6 were used as positive controls for IRE1 $\alpha$. Proteins $(25 \mu \mathrm{g})$ extracted from whole-cell lysates were size-fractionated by SDS-PAGE and immunoblotted with anti-phospho-IRE $1 \alpha^{\text {Ser724 }}$ antibodies. Equal loading of proteins was demonstrated by immunoblotting with an antibody directed against $\beta$-actin. The experiment was replicated three times and representative autoradiographs are presented. (b) MCF-7 cells were incubated with thapsigargin (1 $\mu \mathrm{M})$ and/or IGF-I (10 nM) for 1 , 3 and $6 \mathrm{~h}$. Control cultures were maintained in serum-free medium. Total RNA extracted from whole-cell lysates was subjected to reverse transcription and the cDNA obtained was subjected to PCR. Reaction product was size-fractionated in agarose gel and unspliced ( $480 \mathrm{bp}$ ) and spliced (454 bp) XBP-1 transcripts were visualized by ultraviolet shadowing. (c) MCF-7 cells were incubated with thapsigargin ( $1 \mu \mathrm{M})$ and/or IGF-I (10 nM) for 1,3 and $6 \mathrm{~h}$. Proteins from nuclear extracts $(25 \mu \mathrm{g})$ were size-fractionated by SDS-PAGE and immunoblotted with anti-XBP-1 or anti-ATF6 $\alpha$ antibodies. Equal loading of proteins was demonstrated by immunoblotting with an antibody directed against PARP. The experiment was replicated three times and representative autoradiographs are presented. (d) Purity of nuclear and cytosolic extracts was demonstrated by western blot analysis with anti-PARP and anti-GAPDH antibodies, respectively. The results of densitometric analysis are presented as a fold change compared to untreated cells. Statistically significant difference is represented as follows: $P<0.05$ versus untreated (*) or thapsigargin-treated (\#) cultures (Student's $t$-test)

\begin{abstract}
Ablation of individual components of the ER stress signalling system does not alter the antiapoptotic activity of IGF-I. To elucidate the role of individual components of the ER stress-signalling system in the antiapoptotic activity of IGF-I during ER stress, we employed immortalized mouse embryo fibroblasts with genetic ablation of PERK, ATF4, ATF6 $\alpha, A T F 6 \beta$, IRE $1 \alpha / \beta$ and $X B P 1$. The results of these experiments demonstrate that abrogation of the PERK/ATF4 and ATF6 signalling results in enhancement of thapsigargin-induced apoptosis, whereas blockade of IRE1/XBP1 pathway attenuates apoptosis, suggesting an antiapoptotic function of PERK/ ATF4 and ATF6 pathways during ER stress (Figure 6).
\end{abstract}

However, ablation of individual components of the ER stresssignalling system does not affect the protective activity of IGF-I. It is known that expression of some genes induced by ER stress can be equally induced by PERK/ATF4, IRE1/ XBP1 and ATF6 pathways. Therefore, it is conceivable that blockade of individual components of ER stress-signalling system is compensated for by alternate pathways, implying high plasticity of the ER-stress pathways.

IGF-I increases cellular pool of Grp78/BiP and improves the chaperone reserve. The induction of genes encoding molecular chaperones is part of ER-stress recovery program. ER-resident molecular chaperones facilitate protein folding 

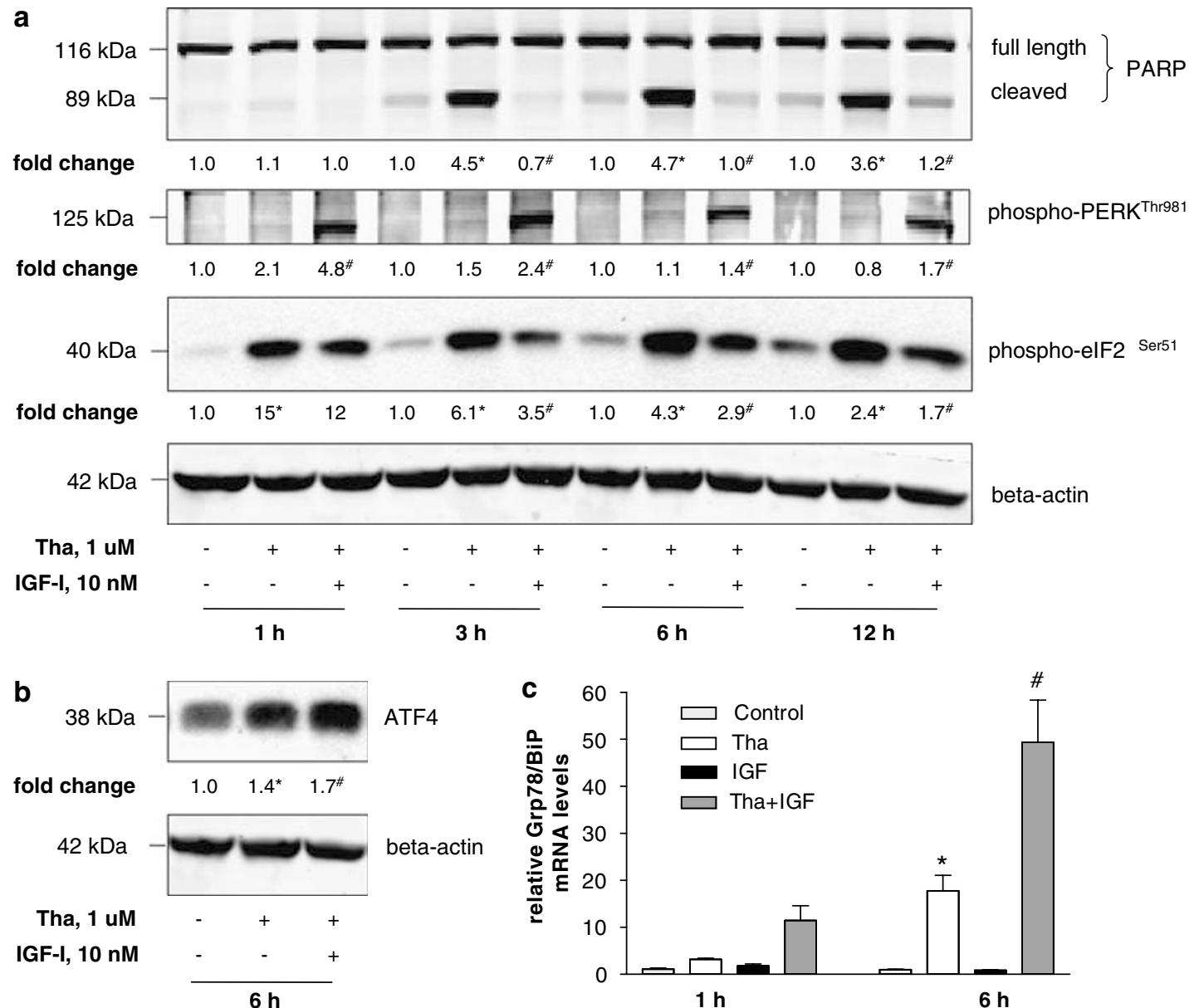

phospho-PERK Thr981
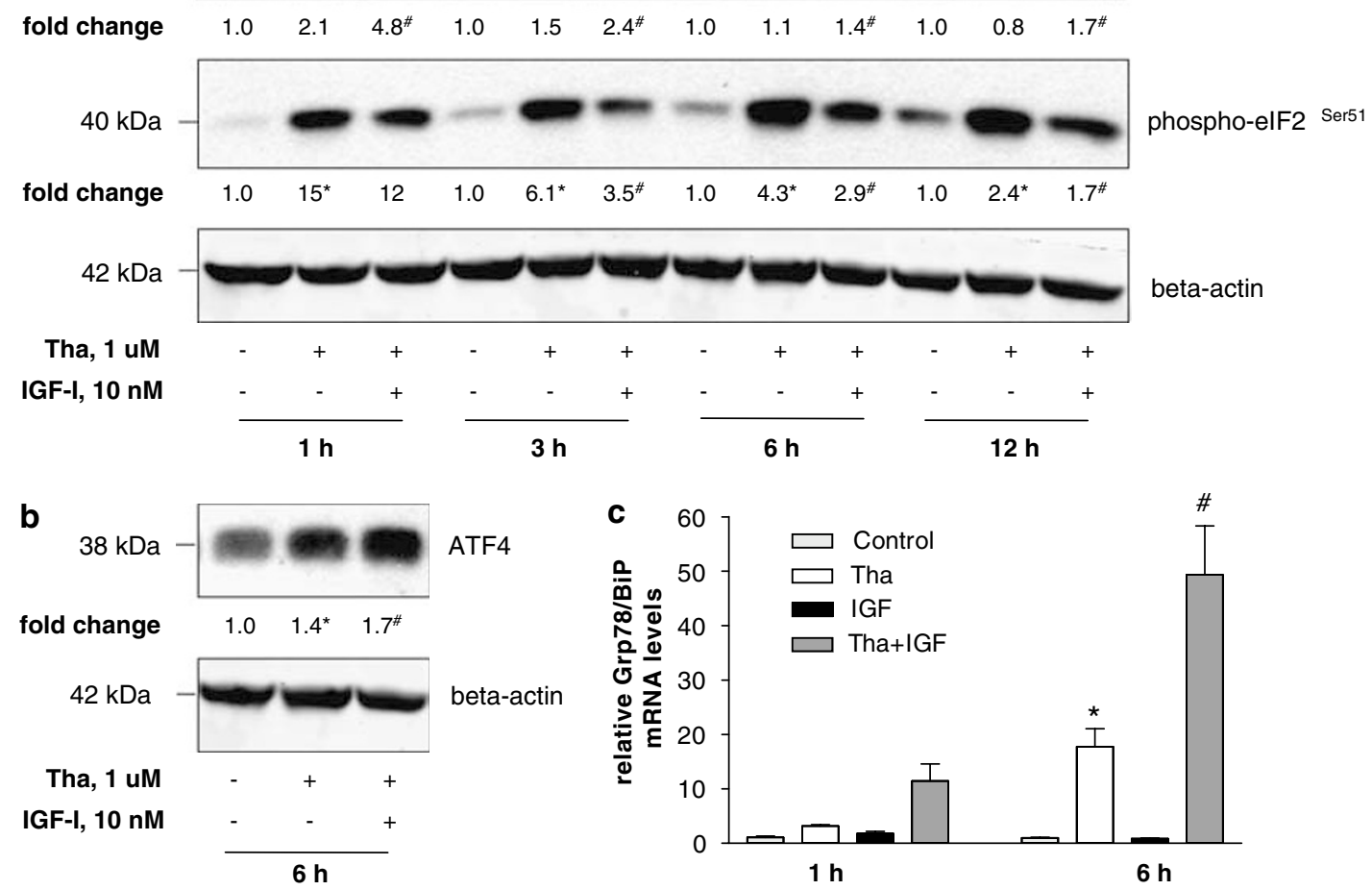

Figure 4 (a) MCF-7 cells were incubated with thapsigargin ( $1 \mu \mathrm{M})$ and/or IGF-I (10 nM) for 1, 3, 6 and $12 \mathrm{~h}$. (b) MCF-7 cells were incubated with thapsigargin ( $1 \mu \mathrm{M})$ and/or IGF-I $(10 \mathrm{nM})$ for $6 \mathrm{~h}$. Control cultures were maintained in serum-free medium. Proteins $(25 \mu \mathrm{g})$ extracted from whole-cell lysates were size-fractionated by SDS-PAGE and immunoblotted with anti-PARP, anti-phospho-PERK ${ }^{\text {Thro81 }}$ anti-elF2 $\alpha^{\text {Ser51 }}$ (a) and anti-ATF4 (b) antibodies. Equal loading of proteins was demonstrated by immunoblotting with an antibody directed against $\beta$-actin. The experiment was replicated three times and representative autoradiographs are presented. The results of densitometric analysis are presented as a fold change compared to untreated cells. Statistically significant difference is represented as follows: $P<0.05$ versus untreated (*) or thapsigargin-treated (\#) cultures (Student's t-test). (c) MCF-7 cells were incubated with thapsigargin $(1 \mu \mathrm{M})$ and/or IGF-I (10 nM) for $1 \mathrm{and} 6 \mathrm{~h}$. Control cultures were maintained in serum-free medium. Grp78/BiP gene expression was analyzed by quantitative RT-PCR. Total RNA extracted from whole-cell lysates was subjected to reverse transcription and the cDNA obtained was subjected to quantitative RT-PCR. Average expression values normalized to $\beta$-actin \pm S.E.M. are shown. Statistically significant difference is represented as follows: $P<0.05$ versus untreated $\left(^{*}\right)$ or thapsigargin- treated (\#) cultures (Student's $t$-test)

by shielding unfolded regions from surrounding proteins. ${ }^{4}$ Grp78/BiP is one of the key HSP70-class molecular chaperones. In addition, Grp78/BiP sequesters the luminal domains of IRE1, ATF6 and PERK, and blocks the active sites of these molecules. ${ }^{21,22}$ Upon induction of ER stress, Grp78/BiP is released into the ER lumen, resulting in activation of IRE1-, ATF6- and PERK-signalling pathways. In turn, active XBP-1 and ATF-6 positively regulate Grp78/ BiP gene expression. ${ }^{4}$ Our data demonstrate that induction of ER stress by thapsigargin is accompanied by an increase in the cellular pool of Grp78/BiP. Furthermore, addition of IGF-I markedly increases Grp78/BiP mRNA and protein levels, thereby improving the chaperone reserve and interfering with the first steps of ER-stress signal transduction (Figures $4 \mathrm{c}$ and $5 \mathrm{a}$ ).

Protective effect of IGF-I against ER stress-induced apoptosis is not mediated by its canonical signalling pathways and does not require de novo protein biosynthesis. To determine which signalling pathways mediate the antiapoptotic activity of IGF-I during ER stressinduced apoptosis, MCF-7 and NIH/3T3 cells were preincubated with inhibitors of MAPK/ERK kinase (MEK), p38 kinase, JNK and PI3K for $12 \mathrm{~h}$ prior to addition of thapsigargin with or without IGF-I. The blockade of any individual enzyme alone did not abrogate the antiapoptotic activity of IGF-I during thapsigargin-induced apoptosis in MCF-7 and NIH/3T3 cells (Figure 7a and b). Since inhibition of a single signalling pathway may result in hyperactivation of alternative pathway(s), we employed a combinatorial blockade of PI3K and MAPK pathways as well (Figure 7c and d). However, results of these experiments demonstrated that simultaneous inhibition of PI3K (or Akt) and MEK or JNK did not abrogate or attenuate the antiapoptotic activity of IGF-I during ER stress in MCF-7 (Figure 7c) and NIH/3T3 cells (Figure 7d). Moreover, since in certain cellular contexts 


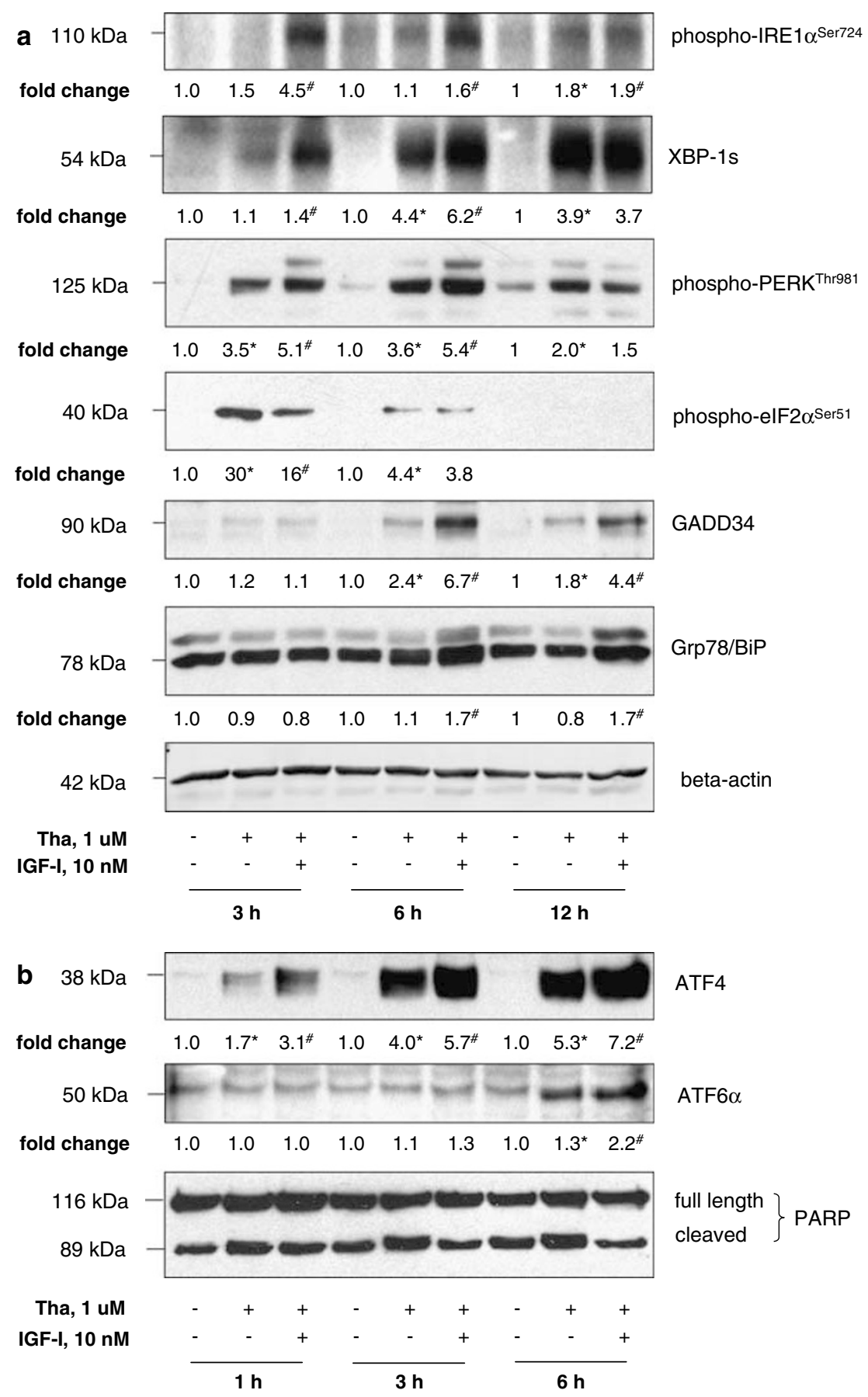

Figure 5 (a) NIH/3T3 fibroblasts were incubated with thapsigargin $(1 \mu \mathrm{M})$ and/or IGF-I (10 nM) for 3, 6 and $12 \mathrm{~h}$. (b) NIH/3T3 fibroblasts were incubated with thapsigargin $(1 \mu \mathrm{M})$ and/or IGF-I $(10 \mathrm{nM})$ for 1,3 and $6 \mathrm{~h}$. Control cultures were maintained in serum-free medium. Proteins $(25 \mu \mathrm{g})$ extracted from whole-cell lysates (a) and nuclear extracts (b) were size-fractionated by SDS-PAGE and immunoblotted with anti-phospho-IRE1 $\alpha^{\text {Ser724 }}$ anti-XBP-1, anti-phospho-PERK ${ }^{\text {Thro81 }}$ anti-elF2 $\alpha^{\text {Ser51 }}$ anti-GADD34, anti-Grp78/BiP, anti-ATF4 and anti-ATF6 $\alpha$ antibodies. Equal loading of proteins was demonstrated by immunoblotting with an antibody directed against $\beta$-actin (a) and PARP (b). The experiment was replicated three times and representative autoradiographs are presented. Statistically significant difference is represented as follows: $P<0.05$ versus untreated $\left(^{*}\right)$ or thapsigargin-treated (\#) cultures (Student's $t$-test)

the biological effects of IGF-I may be mediated by noncanonical signalling intermediates such as $G$ protein, protein kinase $\mathrm{C}$ and signal transducer and activator of transcription3 (STAT3), we also addressed the role of these molecules in the antiapoptotic activity of IGF-I during ER stress. For this purpose, MCF-7 were preincubated with $\mathrm{H}-89$, a specific protein kinase A (PKA) inhibitor, U73122, which inhibits activation of classical protein kinase C (PKC) isoforms by blocking phospholipase $\mathrm{C}$, staurosporine, which is a broadspectrum PKC inhibitor, and Stattic, a specific STAT3 inhibitor. None of these compounds, however, affected the antiapoptotic activity of IGF-I during thapsigargin-induced 
a

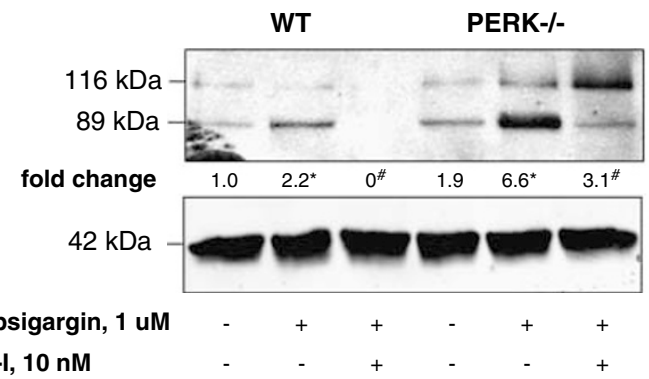

IGF-I, 10 nM
WT
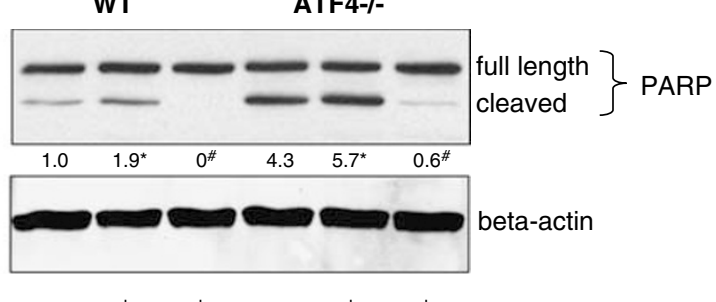

b

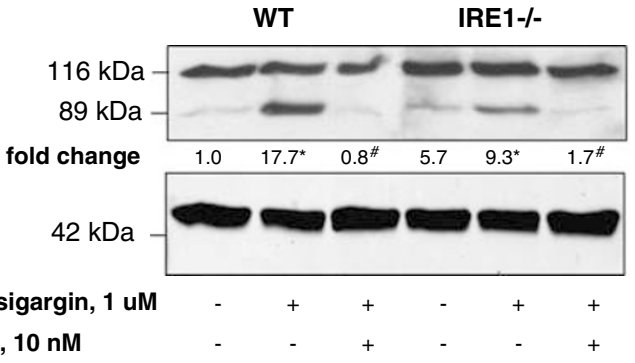

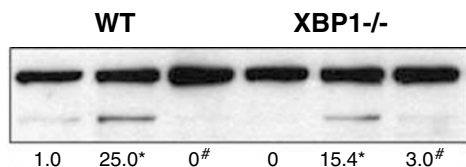

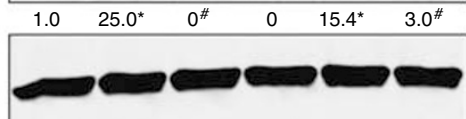

full length cleaved \} PARP
Thapsigargin, $1 \mathrm{uM}$ IGF-I, 10 nM

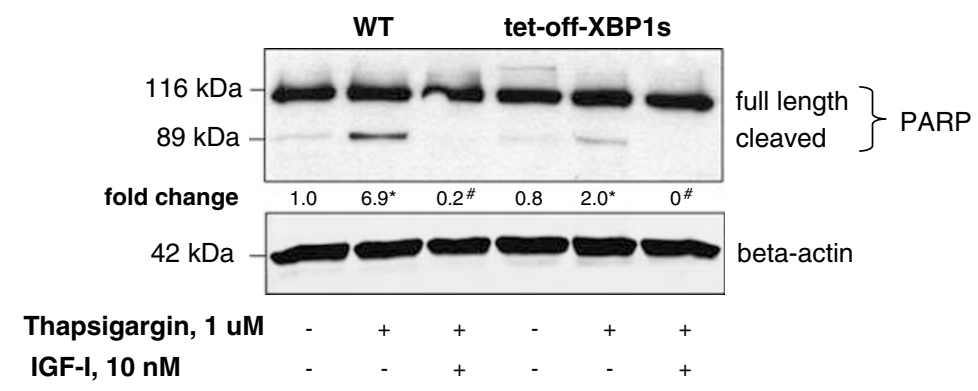

c

WT

iATF6 $\alpha$

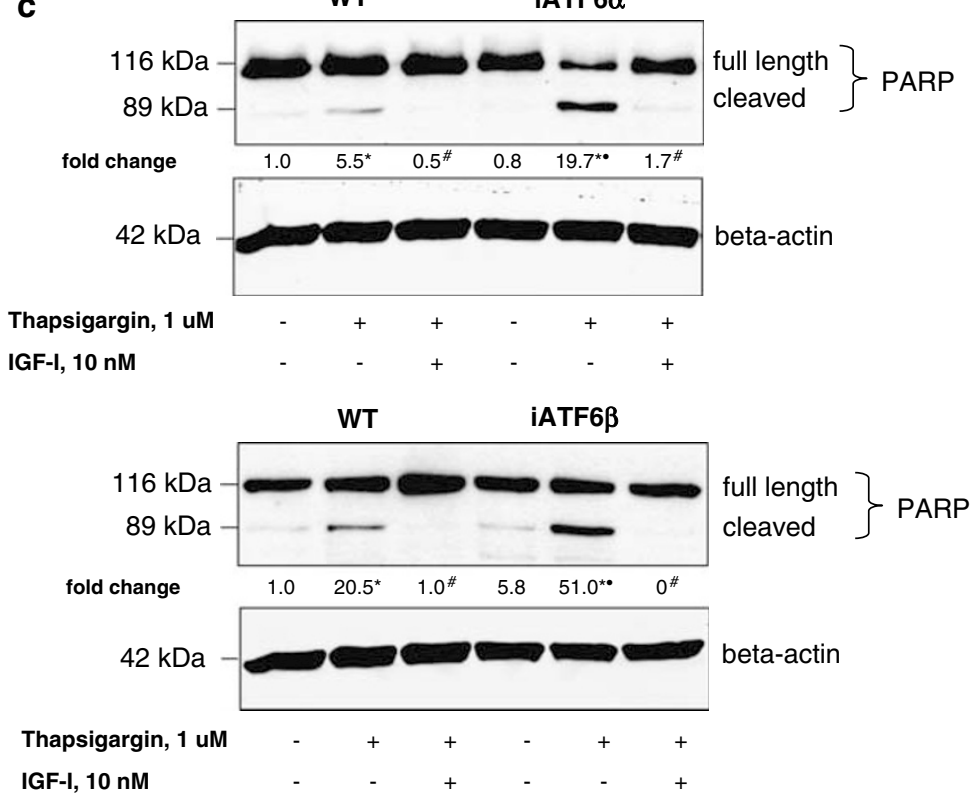

Figure 6 PERK-/-, ATF4-/- (a), IRE1 $\alpha / \beta-/-, X B P 1-/-$, tet-off-XBP1s (b), iATF6 $\alpha$ and iATF6 $\beta$ (knockdown) (c) mouse embryo fibroblasts were incubated with thapsigargin $(1 \mu \mathrm{M})$ and/or IGF-I $(10 \mathrm{nM})$ for $8 \mathrm{~h}$. To block XBP1 induction, tet-off-XBP1s cells and respective wild-type controls were cultured in medium containing doxycycline $(1 \mu \mathrm{g} / \mathrm{ml})$. Control cultures were maintained in serum-free medium. Proteins $(25 \mu \mathrm{g})$ extracted from whole-cell lysates were size-fractionated by SDS-PAGE and immunoblotted with anti-PARP antibodies. Apoptosis was evaluated by PARP cleavage. Equal loading of proteins was demonstrated by immunoblotting with an antibody directed against $\beta$-actin. The experiment was replicated three times and representative autoradiographs are presented. Statistically significant difference is represented as follows: $P<0.05$ versus control $\left(^{*}\right)$, thapsigargin-treated (\#) cultures; thapsigargin-treated mutant cells versus thapsigargin-treated wild-type cells $\left({ }^{\bullet}\right)($ Student's $t$-test) 
apoptosis in MCF-7 cells (data not shown), suggesting that IGF-I protects cells against ER stress-induced apoptosis through a novel, unidentified pathway.

To determine whether the protective effect of IGF-I during ER stress is mediated by proteins synthesized de novo, we blocked protein biosynthesis by cycloheximide. Our results demonstrate that both MCF-7 cells and NIH/3T3 fibroblasts were rescued by IGF-I after preincubation with cycloheximide (Figure 7e-f). Taken together, these data imply that the antiapoptotic effect of IGF-I does not require de novo protein synthesis, and most likely is mediated by posttranslational modifications of target proteins. Importantly, western blot analysis confirmed the specificity and inhibitory activity of the pharmacological blockers at the concentrations used in the present work (data not shown).

\section{Discussion}

The present study identifies IGF-I as a potent protective factor against ER stress-induced apoptosis in both MCF-7 cells and

a

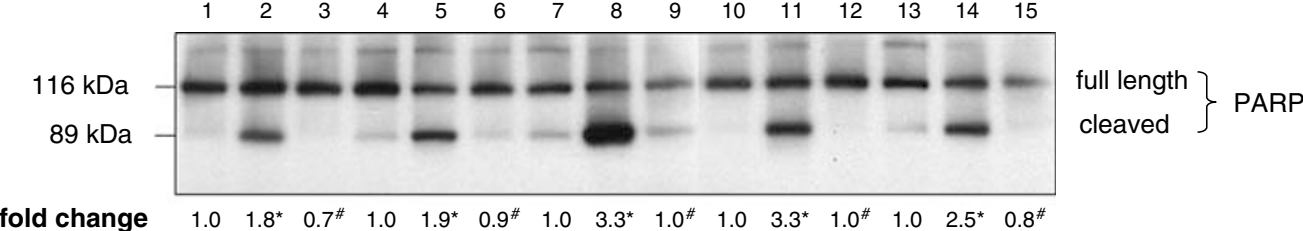

$42 \mathrm{kDa}$

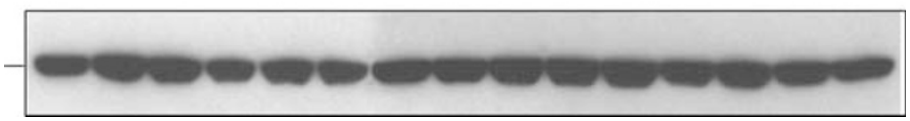

beta-actin

b
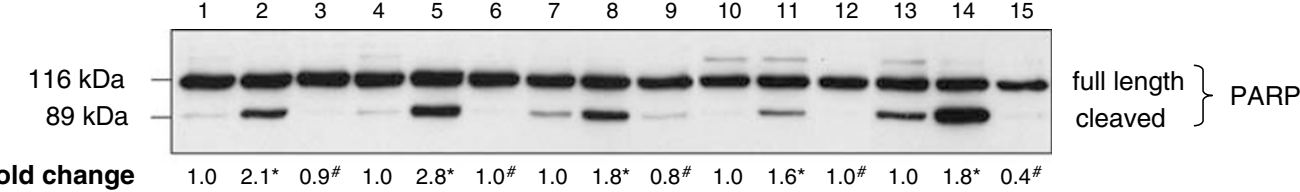

fold change

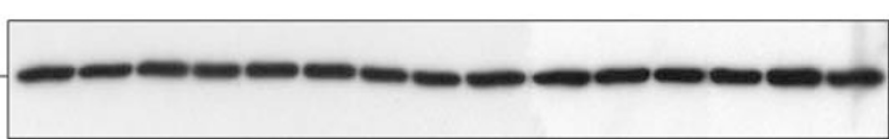

beta-actin

$42 \mathrm{kDa}$

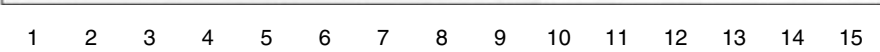

Tha, 1 uM

IGF-I, $10 \mathrm{nM}$

U1026, 5 uM

LY294002, 10 uM

SB203580, 20 uM

SP600125, 20 uM

\section{cleaved}

PARP

$$
\text { (1) }
$$

c $\begin{array}{lllllllllllllllllllllllllll}1 & 2 & 3 & 4 & 5 & 6 & 7 & 8 & 9 & 10 & 11 & 12 & 13 & 14 & 15 & 16 & 17 & 18 & 19 & 20 & 21 & 22 & 23 & 24 & 25 & 26 & 27\end{array}$

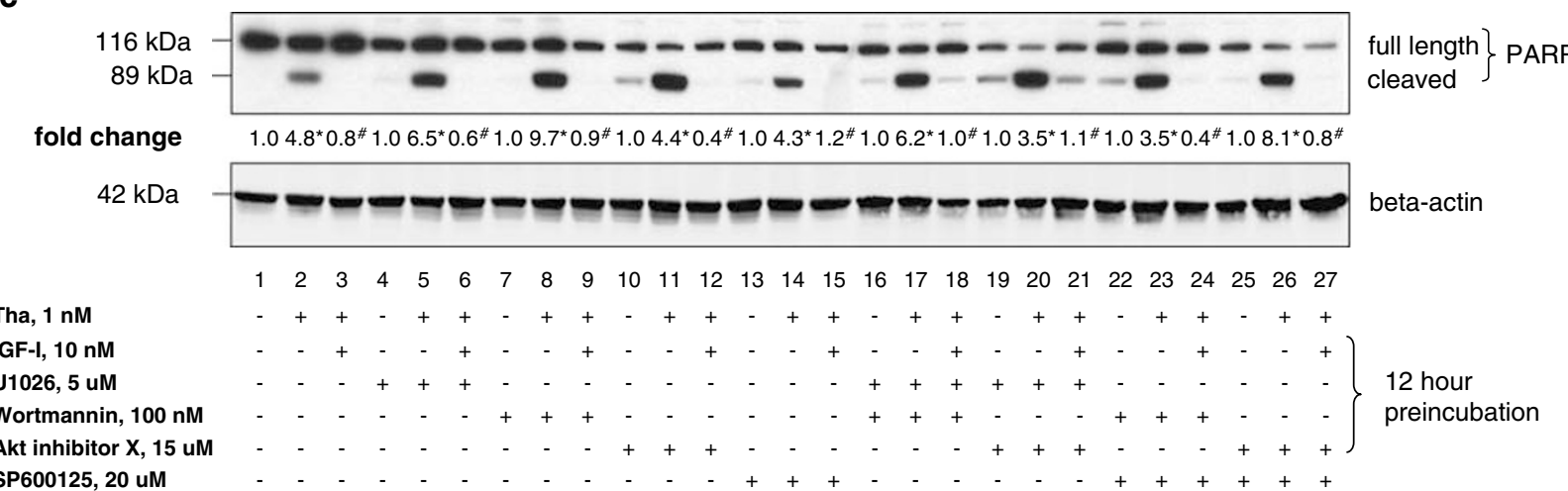

Figure 7 MCF-7 cells $(\mathbf{a}, \mathbf{c}, \mathbf{e})$ and NIH/3T3 fibroblasts $(\mathbf{b}, \mathbf{d}, \mathbf{f})$ were preincubated in serum-free medium in the presence of MEK inhibitor U1026 (5 $\mu \mathrm{M})$, PI3K inhibitors LY294002 (10 $\mu \mathrm{M})$ or wortmannin (100 nM), Akt inhibitor X (15 $\mu \mathrm{M})$, p38 kinase inhibitor SB203580 (20 $\mu \mathrm{M})$ JNK inhibitor SP600125 $(20 \mu \mathrm{M})$ cycloheximide (50 $\mu \mathrm{M})$ for $12 \mathrm{~h}$, and were further incubated with thapsigargin $(1 \mu \mathrm{M})$ and/or IGF-I $(10 \mathrm{nM})$ for $3 \mathrm{~h}$. Control cultures were maintained in serum-free medium. Proteins $(25 \mu \mathrm{g})$ extracted from whole-cell lysates were size-fractionated by SDS-PAGE and immunoblotted with anti-PARP antibodies. Apoptosis was evaluated by PARP cleavage. Equal loading of proteins was demonstrated by immunoblotting with an antibody directed against $\beta$-actin. The experiment was replicated three times and representative autoradiographs are presented. Statistically significant difference is represented as follows: $P<0.05$ versus respective control (*) or thapsigargin-treated (\#) cultures (Student's $t$-test) 


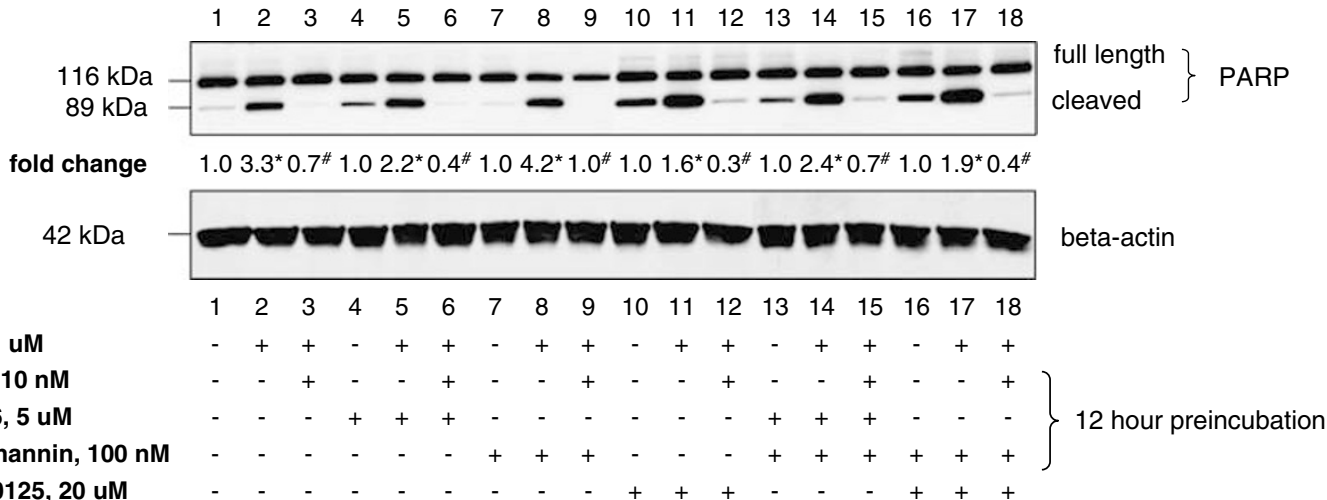

Tha, 1 uM IGF-I, $10 \mathrm{nM}$ U1026, 5 uM Wortmannin, $100 \mathrm{nM}$ SP600125, 20 uM
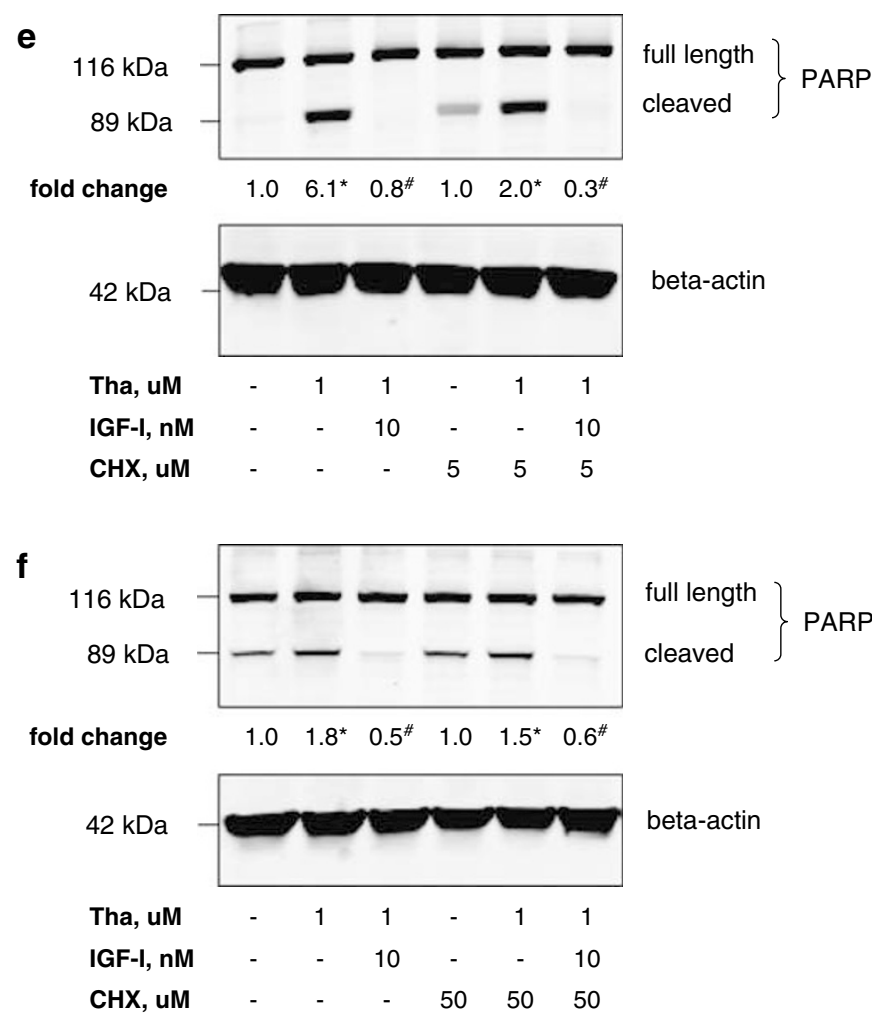

Figure 7 Continued

$\mathrm{NIH} / 3 \mathrm{~T} 3$ fibroblasts. The antiapoptotic activity of IGF-I has been ascribed to multiple signal transduction pathways. ${ }^{24,25}$ The PI3K pathway is considered a major intracellular route that mediates the antiapoptotic activity of IGF-I, but MAPK (ERK1/2, JNK and p38 kinase) pathways are implicated as well. $^{24}$ It has been demonstrated previously that protection against ER stress-induced apoptosis is mediated, at least in part, by the $\mathrm{PI} 3 \mathrm{~K} / \mathrm{Akt} / \mathrm{glycogen}$ synthase-3 $\beta$ pathway. ${ }^{26-29}$ In MCF-7 and NIH/3T3 cells, however, selective inactivation of the PI3K, ERK1/2, JNK or p38 kinase pathway is not sufficient to block the protective effect of IGF-I during ER stress. The antiapoptotic activities of PI3K and MAPK pathways often involve identical molecular targets. ${ }^{24}$ Therefore, it is conceivable that inhibition of a single signalling pathway may result in hyperactivation of alternative pathway(s). For instance, activity of the proapoptotic protein Bad can be blocked by IGF-I through phosphorylation of several serine residues. In the murine hemopoietic 32D cell line, serine phosphorylation of Bad can be mediated by multiple signalling pathways. The main antiapoptotic pathway of the IGF-IR in these cells is a well-characterized IRS-1/PI3K/Akt pathway. However, in the absence of IRS-1, the IGF-IR uses at least two alternative pathways. One of them is the MAPK pathway, and the second is a unique pathway involving 14-3-3mediated mitochondrial translocation of Raf-1. ${ }^{30}$ Our data demonstrate that the simultaneous inhibition of PI3K or Akt and MEK or JNK in both MCF-7 cells and NIH/3T3 fibroblasts, does not abrogate or attenuate the antiapoptotic activity of IGF-I during ER stress, implying plasticity of the known antiapoptotic pathways or activation of other unidentified 
pathway(s). It has previously been demonstrated that in certain cellular contexts IGF-I can transduce intracellular signal through some non-canonical signalling pathways. For instance, it has been reported that IGF-I induces phosphorylation and activation of JAK-1 and JAK-2, and JAK-1 physically interacts with the phosphorylated IGF-IR, ${ }^{31}$ and STAT3 is an important mediator of IGF-I-mediated signal transduction. $^{32}$ In line with these data, our results demonstrate that in both MCF-7 and NIH/3T3 fibroblasts IGF-I is potent inducer of STAT3 phosphorylation. Moreover, in primary cortical neurons, the JAK/STAT pathway mediates IGF-I-dependent cell survival, and the tyrphostin AG490, a specific JAK inhibitor, abrogates the antiapoptotic effect of IGF-I. ${ }^{33}$ The G-protein/adenylyl cyclase/PKA pathway may underlie the IGF-I-mediated antiapoptotic activity as well. It has been shown that in certain cell types, including $\mathrm{NIH} / 3 \mathrm{~T} 3$ fibroblasts, the IGF-IR is coupled with certain types of Gproteins and receptor activation leads to a biologically significant dissociation of G-protein subunits. ${ }^{34}$ Furthermore, the PKA pathway is involved in protection of pancreatic $\beta$-cells from ER stress mediated by GLP-1R agonists. ${ }^{35}$ Finally, IGF-I-mediated antiapoptotic activity during serum starvation suggests involvement of PKC-dependent and MAPK- and PI3K-independent survival pathway(s). ${ }^{36}$ Nevertheless, results of the present study demonstrate that none of the aforementioned pathways mediate the antiapoptotic activity of IGF-I during ER stress. Taken together, these data suggest that a novel pathway(s) is responsible for this biological activity of IGF-I, extending the concept of the IGF-IR as a receptor with a multifaceted signal transduction.

ER stress is accompanied by development of apoptosis only when compensatory mechanisms fail to restore homeostasis in the ER. This adaptive response is initiated by molecular sensors of ER homeostasis, including IRE $1 \alpha$, PERK and ATF6, each of which is capable of transducing a protective signal. Under normal conditions, activity of these proteins is blocked due to Grp78/BiP-mediated sequestration of active sites of their molecules. When ER homeostasis is disturbed, Grp78/BiP is released and IRE1, PERK and ATF6 signalling pathways are activated. ${ }^{4}$ All three arms of the ER stress-signalling system are capable of inducing GADD153/ CHOP expression. ${ }^{7}$ Addition of IGF-I to thapsigargin-treated cells significantly potentiates IRE $1 \alpha$ phosphorylation, which results in elevated intracellular and nuclear levels of XBP-1. IGF-I also enhances accumulation of cleaved ATF6 in the nucleus.

The complex effect of IGF-I on the PERK/elF2 $\alpha /$ ATF4 pathway demonstrates the mechanism whereby the ER transiently shifts from its normal load of secretory proteins toward biosynthesis of stress proteins, thus enhancing the entire folding capacity of the ER. In both MCF-7 and NIH/3T3 cells, PERK phosphorylation and ATF4 levels increase in response to IGF-I, whereas the level of elF $2 \alpha$ phosphorylation decreases. One of the downstream targets of ATF4 is $G A D D 34$, which regulates dephosphorylation of elF $2 \alpha$. GADD34-induced elF2 $\alpha$ dephosphorylation, which is markedly enhanced by IGF-I during ER stress, results in restoration of elF2 $\alpha$ activity. Therefore, it is conceivable that this negative feedback mechanism is stimulated by IGF-I in order to promote translation of chaperone-encoding mRNAs during
ER stress. This hypothesis is supported by our data, which demonstrate that during ER stress, IGF-I significantly increases gene expression and protein levels of Grp78/BiP, a key ER-resident chaperone protein.

The expression of GADD153/CHOP is also significantly increased in the presence of IGF-I. Remarkably, IGF-I alone does not induce GADD153/CHOP synthesis in MCF-7 cells, whereas in NIH/3T3 fibroblasts GADD153/CHOP expression is weakly stimulated by IGF-I in a time-dependent manner. These results are consistent with previously published data that identify IGF-I as a positive regulator of GADD153/CHOP expression in mouse AKR-2B and NIH/3T3 fibroblasts. ${ }^{37}$ GADD153/CHOP is considered a key effector of ER stressinduced apoptosis, but a mechanistic link between GADD153/ $\mathrm{CHOP}$ and cell death has not been identified. Cells deficient in GADD153/CHOP demonstrate resistance to apoptosis induced by tunicamycin and lipopolysaccharide. ${ }^{7,23}$ It is believed that this protein functions as a transcriptional repressor of some antiapoptotic genes, including BCL-2. However, transcriptional profiling failed to prove that GADD153/CHOP regulates major apoptosis-related genes. ${ }^{23}$ In fact, the major genes regulated by GADD153/CHOP (ERO1 $\alpha, G A D D 34$ and WFS1) mediate an adaptive response rather than inducing apoptosis. Moreover, in certain cellular contexts, GADD153/CHOP demonstrates antiapoptotic activity. For instance, in murine models of Pelizaeus-Merzbacher leukodystrophy, a neurodegenerative disease causing diffuse hypomyelination of the central nervous system, GADD153/ CHOP exhibits antiapoptotic activity. ${ }^{38}$ Similarly, incretin hormones, which promote survival of pancreatic $\beta$-cells, also induce GADD153/CHOP expression. ${ }^{35}$ These data suggest that GADD153/CHOP can either promote or inhibit apoptosis. This speculation is further supported by the present study, which demonstrates that SV40 T-antigen-immortalized GADD153/CHOP-deficient mouse embryo fibroblasts are more resistant to apoptosis induced by tunicamycin, whereas sensitivity to thapsigargin-induced cell death is comparable between wild-type and GADD153/CHOP_/- cells. This implies that ER stress induced by different stimuli does not necessarily share the same signalling pathways, and function of certain signalling components can be different depending on the nature of ER stress.

In conclusion, the present study demonstrates that IGF-I is a powerful factor that protects cells from ER stress-induced apoptosis. We believe that the mechanism underlying this phenomenon is stimulation of a compensatory response through a global enhancement of the adaptive capacity of the ER (Figure 8). The signal transduction pathways that are normally used by the IGF-IR do not mediate this biological effect of IGF-I, but other signalling pathways may play a role.

\section{Materials and Methods}

Materials. Chemicals and materials were obtained from commercial sources as indicated: H-89, SB202190, SP600125, staurosporine, thapsigargin, U73122 (Alexis, San Diego, CA, USA); $\beta$-glycerophosphate, Akt inhibitor X, cycloheximide, epoxomicin, Stat3 inhibitor V and U0126 (Calbiochem, San Diego, CA, USA); LY294002 (Cayman Chemical, Ann Arbor, MI, USA); NucleoSpin RNA II kit (Clontech, Mountain View, CA, USA); Tween 20 (Fisher Scientific, Pittsburg, PA, USA); protein-G sepharose 4 fast flow, Rainbow ${ }^{\mathrm{TM}}$ colored protein molecular-weight markers (GE Healthcare Piscataway, Piscataway, NJ, USA); recombinant human IGF-I (Genentech, South San Francisco, CA, USA); bovine serum albumin (BSA), 


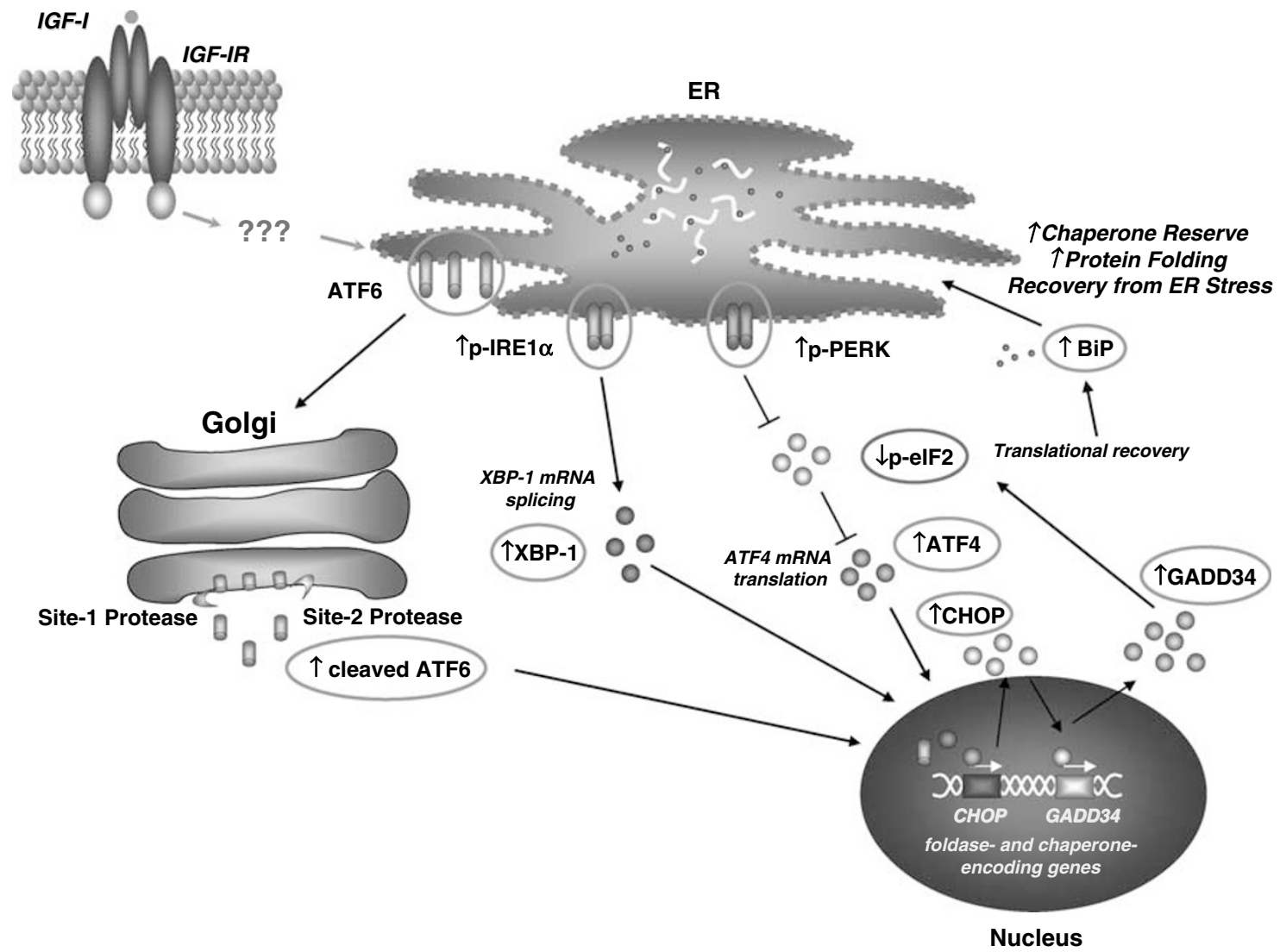

Figure 8 IGF-I and ER stress. IGF-I is a powerful factor that protects cells from ER stress-induced apoptosis. The canonical signal transduction pathways normally used by the IGF-IR (MAPK and PI3K pathways) do not mediate this protective effect. IGF-I markedly enhances the adaptive capacity of the ER, which includes a translational repression as well as a transcriptional program that induces expression of multiple genes that increase the protein folding capacity of the ER and that promote degradation of misfolded proteins. During ER stress, IGF-I significantly enhances the activation of ER stress-signalling pathways, including the IRE1 $\alpha /$ XBP-1, ATF6 and PERK/elF2 $\alpha / A T F 4$ pathways. The complex effect of IGF-I on the PERK/elF2 $\alpha /$ ATF4 pathway represents the mechanism that reprogrammes the ER from its normal load of secretory proteins to the synthesis of stress proteins, which enhance the entire folding capacity of the ER. IGF-I increases PERK phosphorylation and ATF4 levels, but decreases elF2 $\alpha$ phosphorylation. One of downstream targets of ATF4 is GADD153/CHOP, which induces expression of GADD34, a protein that induces dephosphorylation of elF2 $\alpha$ and restoration of elF2 $\alpha$ activity. During ER stress, this negative feedback mechanism is enhanced by IGF-I in order to promote translation of mRNAs encoding molecular chaperones such as Grp78/BiP, whose expression is also markedly upregulated by IGF-I

fetal bovine serum (FBS), L-glutamine, penicillin/streptomycin, trypsin (Gibco, Carlsbad, USA); nitrocellulose membranes, Novex ${ }^{\mathbb{R}}$ Tris-Glycine Gels (Invitrogen, Carlsbad, CA, USA); X-ray films BioMax MR films (Kodak, Rochester, NY, USA); Dulbecco's modified Eagle's medium (DMEM), improved MEM (Mediatech, Herndon, VA, USA); BCA protein assay, bovine albumin, SuperSignal ${ }^{\circledR}$ West Pico chemiluminescent substrate (Pierce, Indianapolis, IN, USA); nuclear extraction kit (Panomics, Fremont, CA, USA); CHAPS, Complete ${ }^{\mathbb{R}}$ Protease Inhibitor Cocktail (Roche, Indianapolis, IN, USA); SB203580 (Santa Cruz Biotechnology, Santa Cruz, CA, USA); $\beta$-estradiol, brefeldin A, dithiothreitol, sodium fluoride, sodium orthovanadate, tetrasodium pyrophosphate, tunicamycin (Sigma-Aldrich, Saint Louis, MO, USA).

Antibodies. The following antibodies and sera were purchased from commercial sources as indicated: rabbit polyclonal antisera against ATF4 (C-20), ATF6 $\alpha$ (H-280), GADD153/CHOP (R20), phospho-PERK (Thr981), XBP-1 (M-186) (Santa Cruz Biotechnology); rabbit polyclonal antisera against phospho-elF2 $\alpha$ (Ser51), PARP (Cell Signalling, Beverly, MA, USA); mouse monoclonal antibody raised against GAPDH (RDI, Concord, MA, USA); rabbit polyclonal antiserum against Grp78/BiP (ET-21) and mouse monoclonal antibody raised against $\beta$-actin (clone AC-15) (Sigma-Aldrich) and secondary peroxidase-conjugated antibodies (GE Healthcare Piscataway). Rabbit polyclonal antiserum against phospho-IRE1 $\alpha$ (Ser724) was generously donated by Dr Fumihiko Urano (Worcester, MA, USA).
Primers. To detect unspliced and spliced variants of XBP-1 by PCR-based assay, the following primers were used (Operon, Huntsville, AL, USA): $5^{\prime}$ AAACAGAGTAGCAGCTCAGACTGC-3' ${ }^{\prime}$ and $5^{\prime}$-TCCTTCTGGGTAGACCTCTGG GAG- $3^{\prime}{ }^{23}$ For real-time PCR analysis, sequences of oligonucleotide primers used were as follows: $\beta$-actin, $5^{\prime}$-CTGGGAGTGGGTGGAGGC- $3^{\prime}$ and $5^{\prime}$-TCAACTGGT CTCAAGTCAGTG-3'; Grp78/BiP, $5^{\prime}$-GGCCGCACGTGGAATG-3' and $5^{\prime}$-ACCTCC AATATCAACTTGAATGTATGG- $3^{\prime}$.

Cell cultures and treatment. Human mammary carcinoma MCF-7, human prostate carcinoma PC-3 cells and mouse NIH/3T3 fibroblasts were obtained from American Type Culture Collection (Manassas, VA, USA) and cultured as reported before. ${ }^{17,39,40}$ Immortalized GADD153/CHOP-/-, PERK-/-, ATF4-/-, IRE1 $\alpha$ / $\beta-/-$, XBP1-/-, tet-off-XBP1s, iATF6 $\alpha$, iATF6 $\beta$ mouse embryo fibroblasts were received from laboratories of Dr David Ron (Skirball Institute, NYU School of Medicine, New York, NY, USA) and Dr Laurie H Glimcher (Department of Immunology and Infectious Diseases, Harvard School of Public Health, Boston, MA, USA) and cultured in DMEM supplemented with $10 \% \mathrm{FBS}, 100 \mathrm{U} / \mathrm{ml}$ penicillin, $100 \mu \mathrm{g} / \mathrm{ml}$ streptomycin and $300 \mu \mathrm{g} / \mathrm{ml}$ L-glutamine. To abrogate XBP1 expression in tet-off-XBP1s MEFs, cells and respective wild-type controls were cultured in medium containing doxycycline $(1 \mu \mathrm{g} / \mathrm{ml})$. Cells were grown until $80 \%$ confluence. Before addition of stimuli, cell cultures were washed in phosphate-buffered saline (PBS), maintained in serum-free culture medium supplemented with $0.1 \%$ BSA for $3 \mathrm{~h}$ and subsequently incubated in the presence or absence of ER-stress inducers IGF-I, estradiol and/or pharmacological inhibitors. Thapsigargin, tunicamycin, 
epoxomicin, U0126, LY294002, wortmannin, SB203580 and SP600125 were dissolved in dimethylsulfoxide, dithiothreitol and Akt inhibitor $X$ in water, and brefeldin $A$ and cycloheximide in methanol. All cultures received the same amount of solvents. After treatment, cells were rinsed in cold PBS and immediately subjected to RNA isolation and protein extraction.

Protein extraction and western blot analysis. Cells were lysed in buffer (pH 7.4) containing $50 \mathrm{mM}$ Tris, $150 \mathrm{mM} \mathrm{NaCl}, 1 \mathrm{mM}$ EDTA, 1.25\% CHAPS, $1 \mathrm{mM}$ sodium orthovanadate, $2 \mathrm{mM}$ sodium fluoride, $10 \mathrm{mM}$ sodium pyrophosphate, $8 \mathrm{mM} \beta$-glycerophosphate and Complete Protease Inhibitor Cocktail. Lysed cells were incubated with slight agitation on ice for $30 \mathrm{~min}$. The insoluble material was removed by centrifugation at $10000 \times g$ for $10 \mathrm{~min}$ at $4{ }^{\circ} \mathrm{C}$. Nuclear and cytosolic fractions of proteins were obtained by a commercially available nuclear extraction kit (Panomics). Concentrations of cellular proteins were determined by BCA protein assay using bovine albumin as a protein standard. A 10-50- $\mu \mathrm{g}$ weight of cell lysates was resuspended in sample buffer, denatured by boiling at $96{ }^{\circ} \mathrm{C}$, subjected to SDS-PAGE (8-10\% acrylamide) and transferred to nitrocellulose membrane. The membrane was sequentially probed with primary and secondary antibodies, incubated with SuperSignal West Pico chemiluminescent substrate and exposed to $X$-ray films. Equal loading of proteins was confirmed by immunoblotting with antibodies to $\beta$-actin.

PCR-based assay for XBP-1 splicing and quantitative real-time RT-PCR. Total RNA was extracted from cells using NucleoSpin RNA II kit. cDNA was prepared from $2 \mu \mathrm{g}$ of total RNA by reverse transcription using oligo(dT) ${ }_{18}$ and Superscript II Reverse Transcriptase (Invitrogen), and PCR reactions were performed using primers flanking the splice site. ${ }^{23}$ The PCR product of unspliced XBP-1 was a 480-bp band, whereas its spliced form was a 454-bp band. Triplicate aliquots of the reverse transcription reactions were used as templates for real-time quantitative PCR using QuantiTect ${ }^{\mathrm{TM}}$ SYBR ${ }^{\circledR}$ Green PCR Master Mix (Qiagen, Valencia, CA, USA) and an ABI PRISM 7900HT Sequence Detection System (Applied Biosystems, Foster City, CA, USA). The PCR product was normalized to $\beta$-actin mRNA. Relative quantification of Grp78/BiP mRNA levels was performed by the $2^{-\Delta \Delta C_{t}}$ method using $C_{\mathrm{t}}$ values obtained from the PCR amplification kinetics with the ABI PRISM SDS 2.2.1 software (Applied Biosystems).

Cell death detection ELISA. Colorimetric enzyme-linked immunosorbent assay (Cell Death Detection ELISA ${ }^{\text {PLUS }}$ ) for quantitative determination of cytoplasmic histone-associated DNA fragments (mono- and oligonucleosomes) was performed according to the manufacturer's instructions (Roche). The results are expressed as relative enrichment of nucleosomes in the cytoplasm of thapsigargin- and thapsigargin//GF-I-treated cells compared to untreated controls.

Densitometric analysis. Densitometric analysis was performed using MacBAS V2.52 software.

Statistical analysis. Results are expressed as the mean \pm S.E.M. Statistical analysis was performed using Student's $t$-test in Microsoft Excel.

Acknowledgements. Dr Danielle Lann was supported by National Institutes of Health Grant T32 DK007792. We thank Dr David Ron (Skirball Institute, NYU School of Medicine, New York, NY, USA) and Dr Laurie H Glimcher (Department of Immunology and Infectious Diseases, Harvard School of Public Health, Boston, MA, USA) for donating GADD153/CHOP-/-, PERK-/-, ATF4-/-, IRE1 $\alpha / \beta-/-$, $X B P 1-/-$, tet-off-XBP1s, iATF6 $\alpha$, iATF6 $\beta$ mouse embryo fibroblasts, and $D r$ Fumihiko Urano (University of Massachusetts Medical School, Worcester, MA, USA) for anti-IRE $1 \alpha$ antibodies. We are also grateful to Drs Ira Tabas and Jerry Arellano (Columbia University, New York, NY, USA) for scientific and technical advice. We also apologize to those colleagues whose publications were not cited owing to space limitations.

1. Orrenius S, Zhivotovsky B, Nicotera P. Regulation of cell death: the calcium-apoptosis link. Nat Rev Mol Cell Biol 2003; 4: 552-565.

2. Danial NN, Korsmeyer SJ. Cell death: critical control points. Cell 2004; 116: 205-219.

3. Kolesnick RN, Kronke M. Regulation of ceramide production and apoptosis. Annu Rev Physiol 1998; 60: 643-665.

4. Schroder M, Kaufman RJ. ER stress and the unfolded protein response. Mutat Res 2005 569: 29-63.
5. Maxfield FR, Tabas I. Role of cholesterol and lipid organization in disease. Nature 2005: 438: 612-621.

6. Xu C, Bailly-Maitre B, Reed JC. Endoplasmic reticulum stress: cell life and death decisions. $J$ Clin Invest 2005; 115: 2656-2664.

7. Oyadomari S, Mori M. Roles of CHOP/GADD153 in endoplasmic reticulum stress. Cell Death Differ 2004; 11: 381-389.

8. Harding HP, Ron D. Endoplasmic reticulum stress and the development of diabetes: a review. Diabetes 2002; 51 (Suppl 3): S455-S461.

9. Hotamisligil GS. Inflammation and metabolic disorders. Nature 2006; 444: 860-867.

10. Ma $Y$, Hendershot LM. The role of the unfolded protein response in tumour development: friend or foe? Nat Rev Cancer 2004; 4: 966-977.

11. Humbel RE. Insulin-like growth factors I and II. Eur J Biochem 1990; 190: 445-462.

12. Cohick WS, Clemmons DR. The insulin-like growth factors. Annu Rev Physiol 1993; 55: 131-153.

13. LeRoith $\mathrm{D}$, Werner $\mathrm{H}$, Beitner-Johnson $\mathrm{D}$, Roberts $\mathrm{Jr} \mathrm{CT}$. Molecular and cellular aspects of the insulin-like growth factor I receptor. Endocr Rev 1995; 16: 143-163.

14. Rubin R, Baserga R. Insulin-like growth factor-I receptor. Its role in cell proliferation, apoptosis, and tumorigenicity. Lab Invest 1995; 73: 311-331.

15. Dupont J, LeRoith D. Insulin and insulin-like growth factor I receptors: similarities and differences in signal transduction. Horm Res 2001; 55 (Suppl 2): 22-26.

16. Monno S, Newman MV, Cook M, Lowe Jr WL. Insulin-like growth factor I activates c-Jun $\mathrm{N}$-terminal kinase in MCF-7 breast cancer cells. Endocrinology 2000; 141: 544-550.

17. Heron-Milhavet L, LeRoith D. Insulin-like growth factor I induces MDM2-dependen degradation of p53 via the p38 MAPK pathway in response to DNA damage. J Biol Chem 2002; 277: 15600-15606.

18. Walsh PT, Smith LM, O'Connor R. Insulin-like growth factor-1 activates Akt and Jun $\mathrm{N}$-terminal kinases (JNKs) in promoting the survival of T lymphocytes. Immunology 2002; 107: 461-471.

19. White MF. IRS proteins and the common path to diabetes. Am J Physiol Endocrinol Metab 2002; 283: E413-E422

20. Toyoshima Y, Karas M, Yakar S, Dupont J, Lee H, LeRoith D. TDAG51 mediates the effects of insulin-like growth factor I (IGF-I) on cell survival. J Biol Chem 2004; 279: 25898-25904.

21. Wu J, Kaufman RJ. From acute ER stress to physiological roles of the unfolded protein response. Cell Death Differ 2006; 13: 374-384.

22. Ron D, Walter $\mathrm{P}$. Signal integration in the endoplasmic reticulum unfolded protein response. Nat Rev Mol Cell Biol 2007; 8: 519-529.

23. Marciniak SJ, Yun CY, Oyadomari S, Novoa I, Zhang Y, Jungreis R et al. CHOP induces death by promoting protein synthesis and oxidation in the stressed endoplasmic reticulum. Genes Dev 2004; 18: 3066-3077.

24. Kooijman R. Regulation of apoptosis by insulin-like growth factor (IGF)-I. Cytokine Growth Factor Rev 2006; 17: 305-323.

25. Kurmasheva RT, Houghton PJ. IGF-I mediated survival pathways in normal and malignant cells. Biochim Biophys Acta 2006; 1766: 1-22.

26. Song L, De SP, Jope RS. Central role of glycogen synthase kinase-3beta in endoplasmic reticulum stress-induced caspase-3 activation. J Biol Chem 2002; 277: 44701-44708.

27. Hu P, Han Z, Couvillon AD, Exton JH. Critical role of endogenous Akt//APs and MEK1/ERK pathways in counteracting endoplasmic reticulum stress-induced cell death. J Biol Chem 2004: 279: 49420-49429.

28. Srinivasan S, Ohsugi M, Liu Z, Fatrai S, Bernal-Mizrachi E, Permutt MA. Endoplasmic reticulum stress-induced apoptosis is partly mediated by reduced insulin signaling through phosphatidylinositol 3-kinase/Akt and increased glycogen synthase kinase-3beta in mouse insulinoma cells. Diabetes 2005; 54: 968-975.

29. Brewster JL, Linseman DA, Bouchard RJ, Loucks FA, Precht TA, Esch EA et al. Endoplasmic reticulum stress and trophic factor withdrawal activate distinct signaling cascades that induce glycogen synthase kinase-3 beta and a caspase-9-dependent apoptosis in cerebellar granule neurons. Mol Cell Neurosci 2006; 32: 242-253

30. Peruzzi F, Prisco M, Dews M, Salomoni P, Grassilli E, Romano G et al. Multiple signaling pathways of the insulin-like growth factor 1 receptor in protection from apoptosis. Mol Cell Biol 1999; 19: 7203-7215.

31. Gual P, Baron V, Lequoy V, Van OE. Interaction of Janus kinases JAK-1 and JAK-2 with the insulin receptor and the insulin-like growth factor-1 receptor. Endocrinology 1998; 139: 884-893

32. Zong CS, Zeng L, Jiang Y, Sadowski HB, Wang LH. Stat3 plays an important role in oncogenic Ros- and insulin-like growth factor I receptor-induced anchorage-independent growth. J Biol Chem 1998; 273: 28065-28072.

33. Yadav A, Kalita A, Dhillon S, Banerjee K. JAK/STAT3 pathway is involved in survival of neurons in response to insulin-like growth factor and negatively regulated by suppressor of cytokine signaling-3. J Biol Chem 2005; 280: 31830-31840.

34. Hallak H, Seiler AE, Green JS, Ross BN, Rubin R. Association of heterotrimeric G(i) with the insulin-like growth factor-l receptor. Release of $G$ (betagamma) subunits upon receptor activation. J Biol Chem 2000; 275: 2255-2258.

35. Yusta B, Baggio LL, Estall JL, Koehler JA, Holland DP, Li H et al. GLP-1 receptor activation improves beta cell function and survival following induction of endoplasmic reticulum stress. Cell Metab 2006; 4: 391-406. 
36. Hurbin A, Coll JL, Dubrez-Daloz L, Mari B, Auberger P, Brambilla C et al. Cooperation of amphiregulin and insulin-like growth factor- 1 inhibits Bax- and Bad-mediated apoptosis via a protein kinase C-dependent pathway in non-small cell lung cancer cells. J Biol Chem 2005; 280: 19757-19767.

37. Entingh AJ, Law BK, Moses HL. Induction of the C/EBP homologous protein (CHOP) by amino acid deprivation requires insulin-like growth factor I phosphatidylinositol 3-kinase, and mammalian target of rapamycin signaling. Endocrinology 2001; 142: 221-228.
38. Southwood CM, Garbern J, Jiang W, Gow A. The unfolded protein response modulates disease severity in Pelizaeus-Merzbacher disease. Neuron 2002; 36: 585-596.

39. Dupont J, Karas M, LeRoith D. The potentiation of estrogen on insulin-like growth factor action in MCF-7 human breast cancer cells includes cell cycle components. J Biol Chem 2000; 275: 35893-35901.

40. Zhao H, Dupont J, Yakar S, Karas M, LeRoith D. PTEN inhibits cell proliferation and induces apoptosis by downregulating cell surface IGF-IR expression in prostate cancer cells. Oncogene 2004; 23: 786-794. 